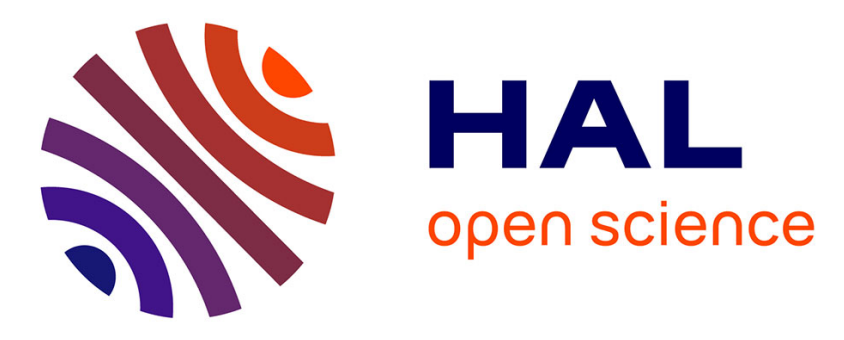

\title{
Modeling the first train timetabling problem with minimal missed trains and synchronization time differences in subway networks
}

Liujiang Kang, Xiaoning Zhu, Huijun Sun, Jakob Puchinger, Mario Ruthmair, $\mathrm{Bin} \mathrm{Hu}$

\section{To cite this version:}

Liujiang Kang, Xiaoning Zhu, Huijun Sun, Jakob Puchinger, Mario Ruthmair, et al.. Modeling the first train timetabling problem with minimal missed trains and synchronization time differences in subway networks. Transportation Research Part B: Methodological, 2016, 93, 10.1016/j.trb.2016.07.006 . hal-01370535

\section{HAL Id: hal-01370535 \\ https://hal.inria.fr/hal-01370535}

Submitted on 22 Sep 2016

HAL is a multi-disciplinary open access archive for the deposit and dissemination of scientific research documents, whether they are published or not. The documents may come from teaching and research institutions in France or abroad, or from public or private research centers.
L'archive ouverte pluridisciplinaire HAL, est destinée au dépôt et à la diffusion de documents scientifiques de niveau recherche, publiés ou non, émanant des établissements d'enseignement et de recherche français ou étrangers, des laboratoires publics ou privés. 


\title{
Modeling the first train timetabling problem with minimal missed
}

\section{trains and synchronization time differences in subway networks}

\author{
Liujiang Kang ${ }^{1,2}$; Xiaoning Zhu ${ }^{1}$; Huijun Sun ${ }^{1}$; Jakob Puchinger ${ }^{3}$ 4; Mario Ruthmair ${ }^{5}$ Bin $\mathrm{Hu}^{6}$ \\ ${ }^{1}$ MOE Key Laboratory for Urban Transportation Complex Systems Theory and Technology, Beijing Jiaotong University, Beijing \\ 100044, China \\ ${ }^{2}$ Centre for Maritime Studies, National University of Singapore, Singapore 117576, Singapore \\ ${ }^{3}$ Institut de Recherche Technologique SystemX, Palaiseau, France \\ ${ }^{4}$ Laboratoire Genie Industriel, CentraleSupélec, Université Paris-Saclay, Chatenay-Malabry, France \\ ${ }^{5}$ Department of Statistics and Operations Research, University of Vienna, Vienna 1090, Austria \\ ${ }^{6}$ Mobility Department, AIT Austrian Institute of Technology, Vienna 1210, Austria
}

\begin{abstract}
Urban railway transportation organization is a systematic activity that is usually composed of several stages, including network design, line planning, timetabling, rolling stock and staffing. In this paper, we study the optimization of first train timetables for an urban railway network that focuses on designing convenient and smooth timetables for morning passengers. We propose a mixed integer programming (MIP) model for minimizing train arrival time differences and the number of missed trains, i.e., the number of trains without transfers within a reasonable time at interchange stations as an alternative to minimize passenger transfer waiting times. This is interesting from the operator's point of view, and we show that both criteria are equivalent. Starting from an intuitive model for the first train transfer problem, we then linearize the non-linear constraints by utilizing problem specific knowledge. In addition, a local search algorithm is developed to solve the timetabling problem. Through computational experiments involving the Beijing subway system, we demonstrate the computational efficiency of the exact model and the heuristic approach. Finally, three practical suggestions are proposed for the operation and management of the urban railway transit system.
\end{abstract}

Key words: First train timetabling; MIP model; Linearization; Heuristic; Case study

\section{Introduction}

\subsection{Motivation}

Urban railway transit is playing an increasingly important role in reducing traffic congestion and 
improving the environment. One of the major roles of metro schedulers is to create timetables for the subway lines of a given network, which is a key component of railway operations and management. According to Ceder et al. (2001), there are three levels of problems that have to be addressed before the actual scheduling and design of timetables can commence: (i) select the type of headway, i.e., periodic or non-periodic timetables, (ii) optimize the departure times of lines and (iii) propose objective functions, such as minimizing operator cost while providing high quality service and minimizing operator and user costs through weighting factors. Then, line operational parameters are optimized to create the whole network timetable. In addition, to comply with variations in travel demand, the day's service can be divided into several time segments (e.g., first train hours, last train hours, peak hours, etc.), where distinct timetabling strategies will be applied (Liebchen, 2008).

Table 1 A snapshot of the first train timetable in the Beijing subway system

\begin{tabular}{|c|c|c|c|c|c|}
\hline Station & $\begin{array}{c}\text { Transfer } \\
\text { direction }\end{array}$ & $\begin{array}{c}\text { Feeder train } \\
\text { arrival time }\end{array}$ & $\begin{array}{c}\text { Transfer } \\
\text { time }\end{array}$ & $\begin{array}{c}\text { Connecting train } \\
\text { departure time }\end{array}$ & $\begin{array}{c}\text { Waiting } \\
\text { time }\end{array}$ \\
\hline \multirow{2}{*}{ GongZhuFen } & L1U $\rightarrow$ L10D & $5: 17: 00$ & $3 \mathrm{~min}$ & $6: 30: 00$ & $70 \mathrm{~min}$ \\
\cline { 2 - 6 } & L1D $\rightarrow$ L10D & $5: 36: 00$ & $3 \mathrm{~min}$ & $6: 30: 00$ & $51 \mathrm{~min}$ \\
\hline \multirow{2}{*}{ GuoMao } & L1D $\rightarrow$ L10D & $5: 05: 00$ & $4.5 \mathrm{~min}$ & $5: 48: 00$ & $38.5 \mathrm{~min}$ \\
\cline { 2 - 6 } & L1D $\rightarrow$ L10U & $5: 05: 00$ & $4.5 \mathrm{~min}$ & $6: 13: 00$ & $63.5 \mathrm{~min}$ \\
\hline
\end{tabular}

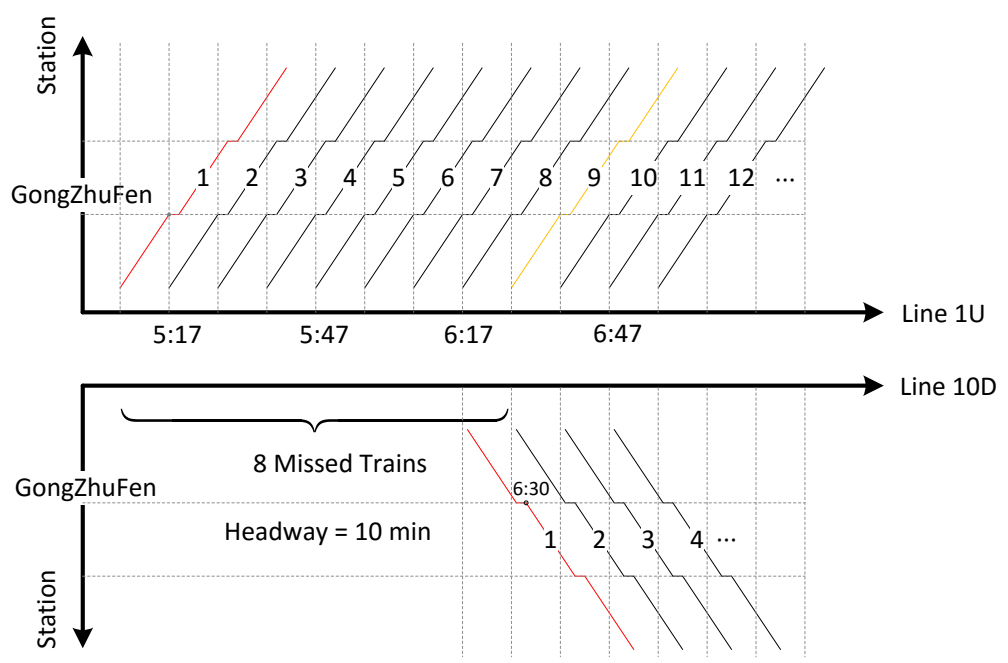

Figure 1 Affiliated problem of long transfer waiting time

Table 1 presents a snapshot of the first train timetable in the Beijing subway system. The first column depicts two different transfer stations, GongZhuFen and GuoMao. The second column shows transfer directions and arrival times of the feeder trains. The third column introduces the necessary transfer times between any two lines. The fourth column provides the departure times of the connecting trains. Based on columns 1-4, the calculated transfer waiting times are listed in the final column of 
Table 1. The Beijing subway network example reveals that the connecting times for first trains is a serious problem. For example, if a passenger takes the first train in the up-train direction of line 1 (L1U) and transfers to the down-train direction of line 10 (L10D) at the GongZhuFen station, a transfer waiting time of 70 min occurs. From another perspective, eight trains on L1U have departed before passengers from L10D arrive. As Figure 1 shows, first train transfers on L10D will board the 9th train on L1U. These trains are denoted as "missed trains" in this paper (Formulations are shown in Section 2).

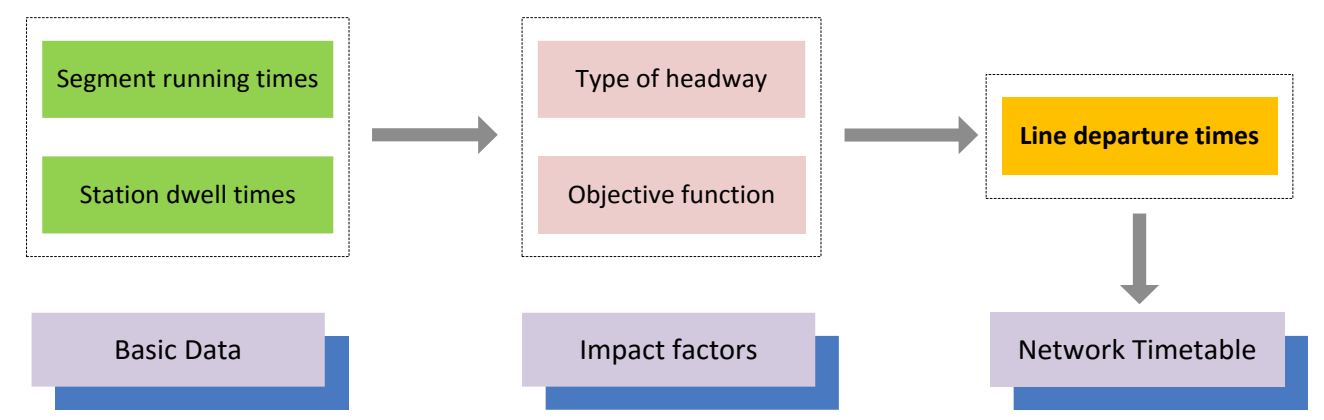

Figure 2 Optimizing first train departure times

The total waiting time for first train transfers in the entire Beijing subway network (year 2013, 240 transfer directions) was more than $2600 \mathrm{~min}$. Note that this value takes into account only the train schedule and does not consider the passengers. Therefore, this paper will study the first train timetabling synchronization problem to provide solutions that will minimize the total transfer waiting time of passengers and minimize the number of missed trains by synchronizing train arrival times at transfer stations, which will allow for well-timed connection transfers. An effective method to avoid the long-waiting-time problem as presented in this paper is depicted in Figure 2. First we collect the operational parameters (segment running times and station dwell times) according to the existing train timetable. Then, the headway and the objective function are determined. Note that under the passenger arrival pattern at stations following uniform distributions, a schedule with a constant headway between consecutive trains can reduce the total waiting time (Niu and Zhou, 2013). In addition, periodic timetables also have the advantage of being easy for passengers to memorize (Barrena et al. 2014). Therefore, we adopt the fixed headway for the Beijing subway system. Finally, first train departure times in the subway network are optimized to minimize the total transfer waiting time of passengers and minimize the number of missed trains. The next section includes a review of the relevant literature before discussing the contributions of this study. 


\subsection{Literature review}

There is a wealth of literature on periodic/non-periodic timetabling problems. Cordeau et al. (1998) presented a survey of optimization models for the most commonly studied train routing and scheduling problems. Guihaire and Hao (2008) presented a global review of the crucial strategic and tactical steps of the design and scheduling of the network. Cacchiani et al. (2014) presented an overview of real-time railway rescheduling. When designing public transport timetables, it is common to optimize an objective function relevant for the operating companies, such as minimizing the operating costs (Ibarra-Rojas et al. 2014), minimizing the train/vehicle running times (Cacchiani and Toth, 2012), maximizing the utilization of energy ( $\mathrm{Li}$ and Lo, 2014) or maximizing the profit earned by the company (Lin and $\mathrm{Ku}, 2014)$.

Chevrier et al. (2013) considered the optimization of the running times, a step in train planning that precedes the timetabling. The calculation was directly related to the construction of speed profiles, which indicate the speed that the trains must hold at each position. Using a directed multi-graph, Caprara et al. (2002) proposed a graph-theoretic formulation for the train timetabling problem in which nodes correspond to departures/arrivals at a certain station at a given time. The formulation was used to derive an integer linear programming model that used the Lagrangian relaxation method. Niu and Zhou (2013) constructed a binary integer programming model incorporated with passenger loading and departure events to optimize a passenger train timetable in a heavily congested urban rail corridor. Fischetti et al. (2009) proposed and computationally analyzed four different methods to improve the robustness of a given train timetabling problem solution for the non-periodic case. Liebchen et al. (2010) studied the design of delay-resistant periodic timetables to optimize the transfer time between two adjacent trains to not only ensure successful transfers but also to minimize total travelling cost.

Real-time railway disruption management is currently an active area of study in Operations Research, and it includes real-time timetable rescheduling and real-time rescheduling of the rolling stock (Cacchiani et al., 2014). From the infrastructure point of view, one widely proposed objective is to minimize the deviation from a solution proposed by the operator. Kang et al. (2015b) minimized the difference between the published timetable and the rescheduled one with train delay conditions. Pellegrini et al. (2014) proposed a mixed-integer linear programming formulation for tackling train routing and scheduling in case of disruption. Yin et al. (2016) proposed a stochastic programming model 
for the metro train rescheduling problem, which was reformulated into a decision-making process. The goal of Cacchiani et al. (2016) was to design conflict-free schedules that differ as little as possible from the ideal ones. They proposed an integer linear programming model for this problem, and the linear programming relaxation of the model was used to derive a dual bound. Because of disruptions, real-time scheduling and routing decisions are frequently made. Lamorgese et al. (2016) presented a mixed integer linear programming model to minimize deviations from the official timetable, and solved it with a Benders'-like decomposition within a suitable master scheme.

In a passenger railroad system, Lin and Ku (2014) addressed the stopping pattern optimization problem to determine the train stopping strategy to maximize the profit made by a rail company. Liu et al. (2013) proposed three objectives to reflect the benefits of bus operator and/or passengers, including minimizing the total waiting time, the total in-vehicle travel time and the total operating cost. Li and Lo (2014) formulated an integrated energy-efficient operation model to jointly optimize the timetable and speed profile to achieve a better performance on the net energy consumption (the difference between the tractive energy consumption and the utilization of regenerative energy). Considering the uncertain train mass, variable tractive force, braking force, and running resistance, Yang et al. (2016) developed a stochastic programming model to determine the timetable and speed profile for the subway system. A simulation-based genetic algorithm incorporated with the optimal control algorithm was designed to solve the model.

Several papers optimize an objective function relevant to passenger waiting time. Kang et al. (2015a) used a mathematical method to reveal the relationships between passenger transfer connection time and passenger transfer waiting time of last subway trains. Wong et al. (2008) presented a mixed-integer programming optimization model for the train synchronization problem for non-periodic timetables that minimized the transfer waiting times of all passengers. Shafhi and Khani (2010) formulated a mixed-integer programming model that gave the departure times of vehicles in lines so that passengers could transfer between lines at transfer stations with minimum waiting times. Niu et al. (2015) studied the train scheduling problem that considers time-dependent demand and skip-stop pattern, and proposed non-linear integer programming models to minimize passenger waiting times.

The following papers considered timetable synchronization in their studies. Ibarra-Rojas and Rios-Solis (2012) formulated a timetabling problem that maximizes the number of synchronizations in a large netwoek to facilitate passenger transfers and avoid bus bunching. Ceder et al. (2001) formulated 
as a mixed-integer linear programming problem to address the problem of generating a timetable for a given network that maximized the number of simultaneous bus arrivals at the transfer nodes. Wu et al. (2015) proposed a timetable synchronization optimization model to optimize passengers' waiting time while limiting the waiting time equitably over all transfer stations, which improves the worst transfer in the subway network.

In a previous paper, Kang et al. (2015a) studied the last train transfer problem, which focused on network connections. Transfer results were mathematically represented by the network accessibility and transfer waiting times. The main difference in approach between the first train timetabling problem and the last train timetabling problem is as follows. In the first train problem, transfers in a complex subway network often face long connecting times that have not been well addressed. This issue has not received enough attention by researchers yet, although it has been raised by the Beijing traffic control center and urban railway transit industry. However the last train problem addresses the transfer possibility, which is a binary problem. Therefore the mathematical models differ substantially. In this paper, we consider the first train transfer problem in a large subway network. Specifically, we first provide a new formulation to precisely describe this problem in mathematical terms. To improve the solution performance of the proposed model, the non-linear constraints are linearized. In addition, a heuristic algorithm is developed to solve the Beijing subway case with a local search method. Solutions obtained by this algorithm for variables, missed trains, passenger waiting time and CPU time, are compared with those by CPLEX to demonstrate the computational efficiency of the exact model and the heuristic approach.

The remainder of this paper is organized as follows. In Section 2 we formally describe the first-train timetabling problem and present two first train timetabling models. In Section 3 we describe our algorithm and test its efficiency with a sample case. Then we present the results of the Beijing subway case in Section 4, and conclusions in Section 5.

\section{Model formulations}

In this section, two indicators, first feeder-connecting time (FFCT) and transfer waiting time (TWT), are introduced to analyze the first train transfer problem. The mathematical relationship between FFCT and TWT is given, and a new first train timetabling model is proposed to minimize the total passenger transfer waiting time and minimize the number of missed trains $n_{s l l^{\prime}}$ that have passed 
through each station $s$ in each line $l^{\prime}$ when the first train passengers of each line $l$ arrive at $s$. The notations used in this paper are listed in Table 2.

\section{Table 2 Notations used in this paper}

\section{Parameters and constants:}

$L \quad$ set of lines in the network, $l \in L$.

$S(l) \quad$ set of stations of line $l$.

$T_{s l l^{\prime}}^{T r a} \quad$ transfer time from line $l$ to $l^{\prime}$ at station $s \in S(l) \cap S\left(l^{\prime}\right)$, and we assume that $T_{s l^{\prime} l}^{T r a}=T_{s l l^{\prime}}^{T r a}$.

$T_{l}^{\min } \quad$ earliest first train service time of line $l$.

$T_{l}^{\max } \quad$ latest first train service time of line $l$.

$H_{l} \quad$ headway of line $l$.

$T_{l s}^{D w} \quad$ train dwell time at station $s \in S(l)$ of line $l$.

$T_{\mathrm{int}}^{D w} \quad$ given train dwell time at an intermediate station.

$T_{\text {tra }}^{D w} \quad$ given train dwell time at a transfer station.

$T_{l s}^{R} \quad$ train running time between the previous station and station $s \in S(l)$ of line $l$.

$v_{s l l^{\prime}} \quad$ number of first train transfer passengers from line $l$ to $l^{\prime}$ at station $s$.

\section{Decision variables:}

$t_{l} \quad$ dispatch time of the first train from vehicle depot of line $l$.

$t_{s l}^{A} \quad$ first train arrival time at station $s \in S(l)$ of line $l$.

$t_{s l}^{D} \quad$ first train departure time from station $s \in S(l)$ of line $l$.

$t_{s l l^{\prime}}^{T W T} \quad$ transfer waiting time from line $l$ to line $l^{\prime}$ at station $s \in S(l) \cap S\left(l^{\prime}\right)$.

$t_{s l l^{\prime}}^{F F C T}$ first feeder-connecting time from line $l$ to line $l^{\prime}$ at station $s \in S(l) \cap S\left(l^{\prime}\right)$.

$n_{s l l^{\prime}} \quad$ the number of missed trains between line $l$ and line $l^{\prime}$ at station $s$.

\subsection{First feeder-connecting time (FFCT) and transfer waiting time (TWT)}

Before modeling the first train timetabling problem, an assumption about the supply of train services is needed. After the first train departs from the vehicle depot, we assume that the following trains in the same line are put into operation continuously with a fixed headway. Therefore, four 
different situations can be identified for first train transfers as shown in Figure 3. Passengers of the first feeder train (FFT) transfer either to the first connecting train (FCT), to the second connecting train or to one of the following connecting trains. In each situation, two types of transfer indicators (FFCT and TWT) are defined.

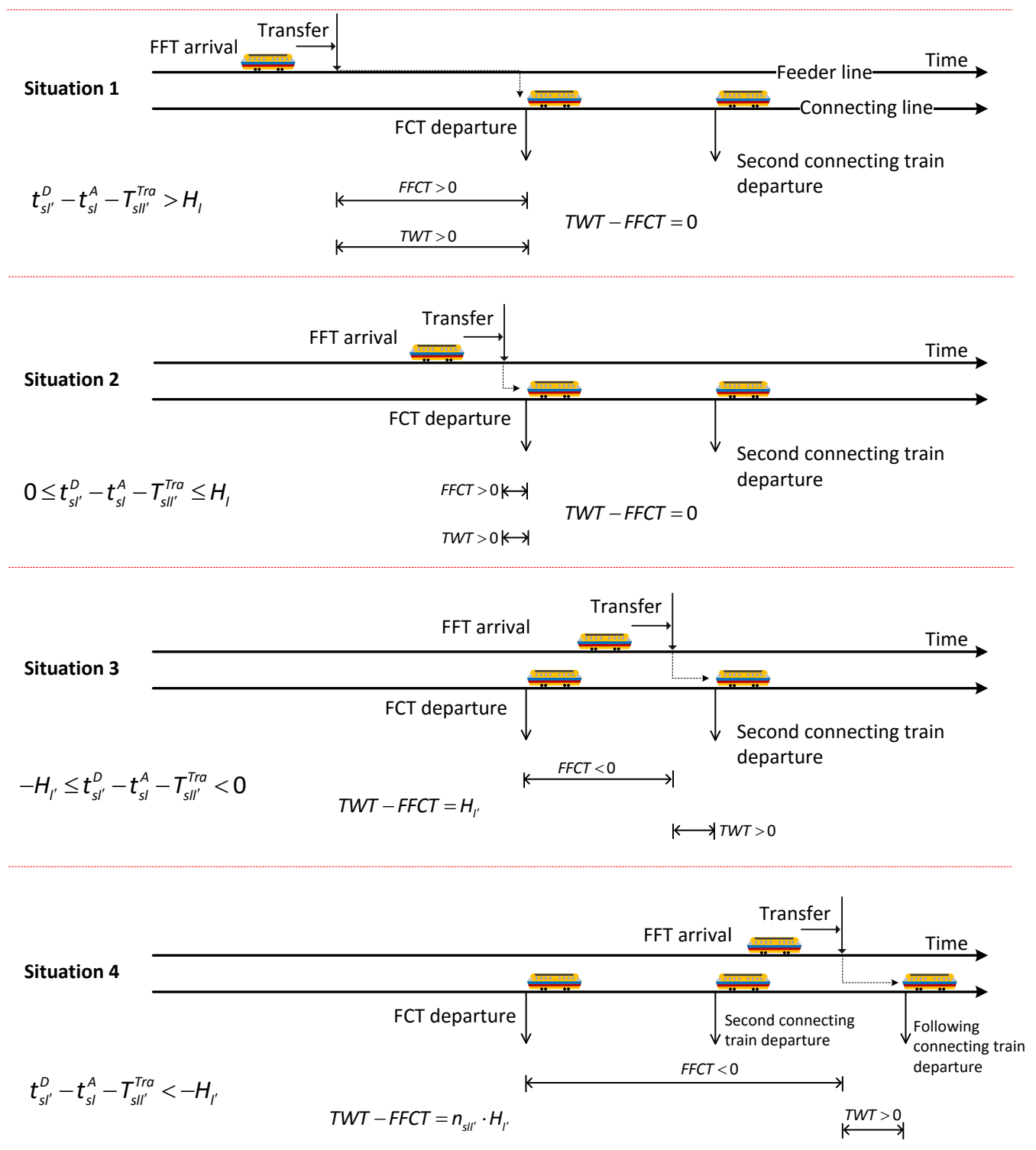

Figure 3 Relationships of FFCT and TWT

The FFCT is influenced by the departure time of the first connecting train and the arrival time of the first feeder passengers, see Equation (1), where $t_{s l^{\prime}}^{D}$ represents the departure time of the FCT of line $l^{\prime}$ from station $s, t_{s l}^{A}$ represents the arrival time of the FFT of line $l$ at station $s$, and $T_{s l l^{\prime}}^{\text {Tra }}$ represents the transfer time between $l$ and $l^{\prime}$ at $s$. The value of FFCT can be positive, negative or zero. 


$$
t_{s l l^{\prime}}^{F F T}=t_{s l^{\prime}}^{D}-t_{s l}^{A}-T_{s l l^{\prime}}^{T r a}
$$

The TWT (which is always positive) is determined by the departure time of the connecting train and the arrival time of the first feeder passengers, see Equation (2), where $H_{l^{\prime}}$ represents the headway of $l^{\prime}$, and $n_{s l l^{\prime}}$ is an integer variable. The value of $n_{s l^{\prime}}$ in Equation (3) denotes the number of trains of line $l^{\prime}$ that have passed by $s$ when the FFT of line $l$ arrives at station $s$, where function $\operatorname{ceil}(A)$ rounds the elements of $A$ to the nearest integer greater than or equal to $A$.

$$
\begin{gathered}
t_{s l l^{\prime}}^{T W T}=t_{s l^{\prime}}^{D}-t_{s l}^{A}-T_{s l l^{\prime}}^{T r a}+n_{s l l^{\prime}} \cdot H_{l^{\prime}} \\
n_{s l l^{\prime}}=\left\{\begin{array}{l}
0, t_{s l^{\prime}}^{D}-t_{s l}^{A}-T_{s l l^{\prime}}^{T r a} \geq 0 \\
\operatorname{ceil}\left(\left|t_{s l^{\prime}}^{D}-t_{s l}^{A}-T_{s l l^{\prime}}^{T r a}\right| / H_{l^{\prime}}\right), \text { otherwise }
\end{array}\right.
\end{gathered}
$$

Case 1: $T W T-F F C T=0$

As illustrated in Figure 3 (situations 1-2), the FFT arrives at $s$ earlier than the FCT. Therefore, passengers on the FFT board the FCT successfully. Such a case can be further divided into two situations, i.e., long waiting time (situation 1) and short waiting time (situation 2).

Case 2: $T W T-F F C T=n_{s l l^{\prime}} \cdot H_{l^{\prime}}$

The FFT arrives at $s$ later than the FCT (situations 3-4). Consequently, passengers on the FFT board the following $n_{s l l^{\prime}}$-th train, where $n_{s l l^{\prime}}$ is defined by Equation (3).

According to Figure 3 and Equations (1-3), the mathematical relationship between FFCT and TWT is presented in Equation (4). The first train TWT can be easily calculated as long as we know the value of FFCT. Moreover, TWT can be fixed when the arrival and departure times of the first feeder and connecting trains are obtained.

$$
t_{s l l^{\prime}}^{T W T}=t_{s l l^{\prime}}^{F F C}+n_{s l l^{\prime}} \cdot H_{l^{\prime}}
$$

\subsection{First train timetable synchronization}

As situation 1 in Figure 3 indicates, if the FFT arrives much earlier than the FCT then the feeder passengers have to wait a long time. Similar to situation 4, if the FFT arrives too late, the passengers on FCT must wait a long time to transfer to line $l$. 


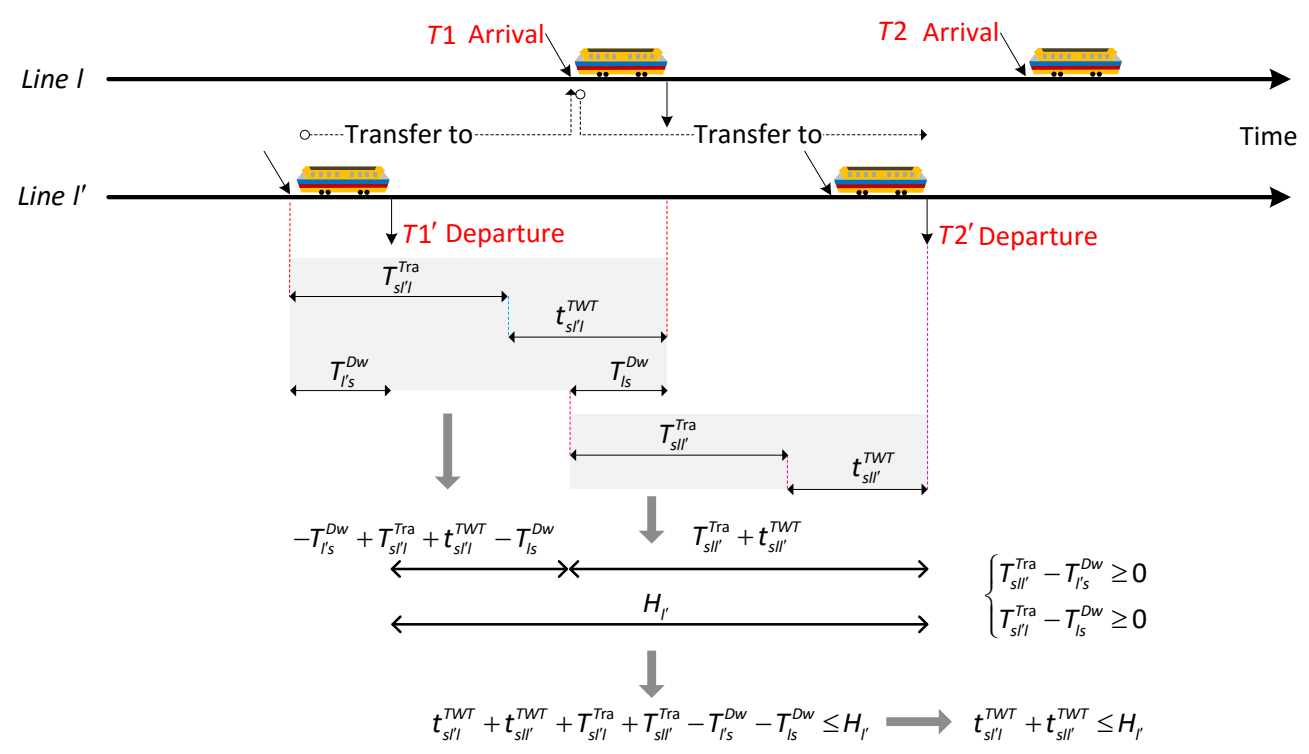

Figure 4 First train timetable synchronization in an ideal situation

Figure 4 shows how two first trains in different lines synchronize at a transfer station in an ideal situation. The time difference between $T 1^{\prime}$ departure and $T 1$ arrival is $-T_{l^{\prime} s}^{D w}+T_{s l^{\prime} l}^{T \mathrm{ra}}+t_{s l^{\prime} l}^{T W T}-T_{l s}^{D w}$. The time difference between $T 1$ arrival and $T 2^{\prime}$ departure is $t_{s l l^{\prime}}^{T r a}+t_{s l l^{\prime}}^{T W T}$. Note that this figure represents the ideal trains' synchronization situation, which cannot be achieved in all station. The first train $T 1$ in line $l$ arrives later than $T 1^{\prime}$ in line $l^{\prime}$, and $T 1$ arrives earlier than the second train $T 2^{\prime}$. In this case, passengers from $T 1^{\prime}$ wait for $T 1$ at worst $H_{l}$ min, and passengers from $T 1$ wait for $T 2^{\prime}$ at worst $H_{l^{\prime}}$ min. In addition, if the timetable is a periodic one, this scenario could be repeated, for example $T 1^{\prime} \rightarrow T 1, T 1 \rightarrow T 2^{\prime}, T 2^{\prime} \rightarrow T 2$, etc. Therefore, the sum of $t_{s l l^{\prime}}^{T W T}$ and $t_{s l^{\prime} t}^{T W T}$ is at worst $H_{l^{\prime}}$ min in ideal situations, see Inequality (5).

$$
0 \leq t_{s l l^{\prime}}^{T W T}+t_{s l^{\prime} l}^{T W T} \leq H_{l^{\prime}}
$$

To allow passengers to inter-transfer smoothly (transfer waiting time within one headway) between the FFT and the FCT, the TWT is minimized:

$$
T=\min \sum_{s \in S(l) \cap S\left(l^{\prime}\right)} \sum_{l \in L} \sum_{l^{\prime} \in L} v_{s l l^{\prime}} \cdot t_{s l l^{\prime}}^{T W T}
$$

where $v_{s l l^{\prime}}$ represents the number of first train transfer passengers from line $l$ to $l^{\prime}$ at station $s$. Note that a different volume and spatial distribution of the first train transfer passengers in the network will lead to a different timetable and total TWT. In this paper, values of $v_{\text {sll }}$ are constant. 


\subsection{New first train timetabling model}

As mentioned above, two indicators, FFCT and TWT, are proposed to evaluate the first train transfers. If the FFT and the FCT synchronize at $S$ successfully, then $0 \leq t_{s l l^{\prime}}^{T W T} \leq H_{l^{\prime}}$ and $0 \leq t_{s l^{\prime} l}^{T W T} \leq H_{l}$ holds. Otherwise, one side of transfers may face a long waiting time, i.e., $t_{s l^{\prime \prime l}}^{T W T}>H_{l}$ or $t_{s l l^{\prime}}^{T W W}>H_{l^{\prime}}$. From the perspective of minimum TWT, the objective function (7) minimizes the number of trains that have passed through station $s$ of line $l^{\prime}$ when passengers from the first train of line $l$ arrive at $s$. In addition, objective (7) ensures that the FFT and the FCT synchronize at transfer stations.

$$
N=\min \sum_{s \in S(l) \cap S\left(l^{\prime}\right)} \sum_{l \in L} \sum_{l^{\prime} \in L}\left(v_{s l l^{\prime}} \cdot n_{s l l^{\prime}} \cdot H_{l^{\prime}}+v_{s l^{\prime} l^{\prime}} \cdot n_{s l^{\prime} l} \cdot H_{l}\right)+\sum_{s \in S(l) \cap S\left(l^{\prime}\right)} \sum_{l \in L} \sum_{l^{\prime} \in L}\left(v_{s l l^{\prime}}-v_{s l^{\prime} l^{\prime}}\right) \cdot\left(t_{s l^{\prime}}^{A}-t_{s l}^{A}\right)
$$

Remark 1: The total TWT of optimal solutions obtained by objective function (7) for first train transfers is equivalent to that of objective function (6).

Proof: For any $l \in L, \quad l^{\prime} \in L, \quad s \in S(l) \cap S\left(l^{\prime}\right)$, and inter-transfer directions $\left(l \rightarrow l^{\prime}\right.$ and $\left.l^{\prime} \rightarrow l\right)$, we have $t_{s l l^{\prime}}^{T W T}=t_{s l^{\prime}}^{D}-t_{s l}^{A}-T_{s l l^{\prime}}^{T r a}+n_{s l l^{\prime}} \cdot H_{l^{\prime}}$ and $t_{s l^{\prime} l}^{T W T}=t_{s l}^{D}-t_{s l^{\prime}}^{A}-T_{s l^{\prime} l}^{T r a}+n_{s l^{\prime} l} \cdot H_{l}$. Therefore,

$$
\begin{aligned}
& v_{s l l^{\prime}} \cdot t_{s l l^{\prime}}^{T W T}+v_{s l^{\prime} l} \cdot t_{s l^{\prime} l}^{T W T} \\
& =v_{s l l^{\prime}} \cdot\left(t_{s l^{\prime}}^{D}-t_{s l}^{A}-T_{s l l^{\prime}}^{T r a}+n_{s l l^{\prime}} \cdot H_{l^{\prime}}\right)+v_{s l^{\prime} l} \cdot\left(t_{s l}^{D}-t_{s l^{\prime}}^{A}-T_{s l^{\prime} l}^{T r a}+n_{s l^{\prime}} \cdot H_{l}\right) \\
& =v_{s l l^{\prime}} \cdot\left(t_{s l^{\prime}}^{A}+T_{l l^{\prime}}^{D w}-t_{s l}^{A}-T_{s l l^{\prime}}^{T r a}+n_{s l l^{\prime}} \cdot H_{l^{\prime}}\right)+v_{s l^{\prime} l^{\prime}} \cdot\left(t_{s l}^{A}+T_{l s}^{D w}-t_{s l^{\prime}}^{A}-T_{s l^{\prime} l}^{T r a}+n_{s l^{\prime} l} \cdot H_{l}\right)
\end{aligned}
$$

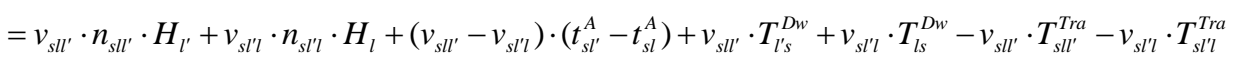

$$
\begin{aligned}
& =v_{s l l^{\prime}} \cdot n_{s l l^{\prime}} \cdot H_{l^{\prime}}+v_{s l^{\prime} l} \cdot n_{s l^{\prime} l} \cdot H_{l}+\left(v_{s l l^{\prime}}-v_{s l^{\prime} l}\right) \cdot\left(t_{s l^{\prime}}^{A}-t_{s l}^{A}\right)+C,
\end{aligned}
$$

where passenger volumes $v_{s l l^{\prime}}$ and $v_{s l^{\prime} l}$ are given based on real data. Polynomial $C=v_{s l l^{\prime}} \cdot T_{l^{\prime} s}^{D w}+v_{s l^{\prime} l} \cdot T_{l s}^{D w}-v_{s l^{\prime}} \cdot T_{s l l^{\prime}}^{T r a}-v_{s l^{\prime} l} \cdot T_{s l^{\prime} l}^{T r a}$ is a constant. Note that the headways $\left(H_{l}\right)$ for the first trains in a subway network are given based on different transit lines. Therefore, the total first train TWT in a subway network can be captured by Equation (9),

$$
\begin{aligned}
& \sum_{s \in S(l) \cap S\left(l^{\prime}\right)} \sum_{l \in L} \sum_{l^{\prime} \in L} v_{s l l^{\prime}} \cdot t_{s l l^{\prime}}^{T W T} \\
= & \frac{1}{2} \sum_{s \in S(l) \cap S\left(l^{\prime}\right)} \sum_{l \in L} \sum_{l^{\prime} \in L}\left(v_{s l l^{\prime}} \cdot t_{s l l^{\prime}}^{T W T}+v_{s l^{\prime} l} \cdot t_{s l^{\prime} l}^{T W T}\right) \\
= & \frac{1}{2} \sum_{s \in S(l) \cap S\left(l^{\prime}\right)} \sum_{l \in L} \sum_{l^{\prime} \in L}\left\{v_{s l l^{\prime}} \cdot n_{s l l^{\prime}} \cdot H_{l^{\prime}}+v_{s l^{\prime} l} \cdot n_{s l^{\prime} \cdot} \cdot H_{l}+\left(v_{s l l^{\prime}}-v_{s l^{\prime}}\right) \cdot\left(t_{s l^{\prime}}^{A}-t_{s l}^{A}\right)+C\right\} \\
= & \frac{1}{2}\left\{\sum_{s \in S(l) \cap S\left(l^{\prime}\right)} \sum_{l \in L} \sum_{l^{\prime} \in L} C+\sum_{s \in S(l) \cap S\left(l^{\prime}\right)} \sum_{l \in L} \sum_{l^{\prime} \in L}\left(v_{s l l^{\prime}} \cdot n_{s l l^{\prime}} \cdot H_{l^{\prime}}+v_{s l^{\prime} l^{\prime}} \cdot n_{s l^{\prime} l^{\prime}} \cdot H_{l}\right)+\sum_{s \in S(l) \cap S\left(l^{\prime}\right)} \sum_{l \in L} \sum_{l^{\prime} \in L}\left(v_{s l^{\prime}}-v_{s l^{\prime} l^{\prime}}\right) \cdot\left(t_{s l^{\prime}}^{A}-t_{s l}^{A}\right)\right\}
\end{aligned}
$$


$=\Delta+\frac{1}{2}\left\{\sum_{s \in S(l) \cap S\left(l^{\prime}\right)} \sum_{l \in L} \sum_{l^{\prime} \in L}\left(v_{s l l^{\prime}} \cdot n_{s l l^{\prime}} \cdot H_{l^{\prime}}+v_{s l^{\prime} l} \cdot n_{s l^{\prime} l^{\prime}} \cdot H_{l}\right)+\sum_{s \in S(l) \cap S\left(l^{\prime}\right)} \sum_{l \in L} \sum_{l^{\prime} \in L}\left(v_{s l l^{\prime}}-v_{s l^{\prime} l}\right) \cdot\left(t_{s l^{\prime}}^{A}-t_{s l}^{A}\right)\right\}$,

where $\Delta=\frac{1}{2} \sum_{s \in S(l) \cap S\left(l^{\prime}\right)} \sum_{l \in L} \sum_{l^{\prime} \in L} C$ is a constant.

Therefore, objective function (7) can achieve the minimum TWT for first train transfers in subway systems.

\subsection{Constraints of the first train timetabling}

This section gives the following six constraints for the first train timetabling, including arrival times at stations, departure times from stations, departure times from vehicle depots, segment running times, station dwell times and line headways.

The first train arrival time at station $s$ in line $l$ can be tracked by Equation (10), where $t_{l}$ denotes the departure time from the vehicle depot in line $l, T_{l s}^{R}$ denotes the running time between the previous station and station $s$ in line $l$, and $T_{l s}^{D w}$ denotes the dwell time at station $s$ in line $l$.

$$
t_{s l}^{A}=t_{l}+\sum_{k=1}^{s} T_{l k}^{R}+\sum_{k=1}^{s-1} T_{l k}^{D w}
$$

Similarly, the first train departure time at station $s$ in line $l$ is captured by Equation (11).

$$
t_{s l}^{D}=t_{s l}^{A}+T_{l s}^{D w}=t_{l}+\sum_{k=1}^{s} T_{l k}^{R}+\sum_{k=1}^{s} T_{l k}^{D w}
$$

The first train departure time from the vehicle depot is limited by Equation (12), where $T_{l}^{\min }$ represents the earliest first train service time and $T_{l}^{\max }$ represents the latest service time.

$$
T_{l}^{\min } \leq t_{l} \leq T_{l}^{\max }
$$

Segment running times are obtained based on the original Beijing subway timetable, as published in 2014.

Stations are divided into intermediate stations and transfer stations. In general, trains dwell at stations for different amounts of time depending on passenger flows and various station operations, such as changing the arrival-departure tracks or changing train directions. In subway systems, train dwell times are mainly predetermined according to station types, i.e., intermediate station dwell time $\left(T_{\mathrm{int}}^{D w}\right)$ and transfer station dwell time $\left(T_{\text {tra }}^{D w}\right)$. Therefore, $T_{l s}^{D w}$ is limited to the following Equation (13).

$$
T_{l s}^{D w} \in\left\{T_{\mathrm{int}}^{D w}, T_{\mathrm{tra}}^{D w}\right\}
$$


According to the real data from the Beijing subway system, dwell time in this paper lasts $30 \mathrm{~s}$ at an ordinary station and reaches $60 \mathrm{~s}$ at a transfer station.

Line headways in the Beijing subway depend on the time period. During rush hours (7:00 to 9:00 and 17:00 to 19:00), the headway is $2 \mathrm{~min}$. Generally, the headway during non-rush hour periods is 5 min. The headway for the first/last trains is set to a maximum of $10 \mathrm{~min}$.

\subsection{First-train timetabling models}

The model M1 in Equation (14) is a non-linear model and aims to minimize the total TWT for first train transfers (with passenger volumes $v_{s l l^{\prime}}$ representing the number of first train transfer passengers from line $l$ to $l^{\prime}$ at station $s$ ) in a subway network. Model M1 was adopted from Wong et al. (2008) and Shafhi and Khani (2010) to calculate the total passenger transfer waiting time in a given network.

$$
\begin{gathered}
\mathrm{M} 1: T=\min \sum_{s \in S(l) \cap S\left(l^{\prime}\right)} \sum_{l \in L} \sum_{l^{\prime} \in L} v_{s l l^{\prime}} \cdot t_{s l l^{\prime}}^{T W T} \\
\text { s.t. } t_{s l l^{\prime}}^{T W T}=t_{s l^{\prime}}^{D}-t_{s l}^{A}-T_{s l l^{\prime}}^{T r a}+n_{s l l^{\prime}}, H_{l^{\prime}}, \forall l \in L, l^{\prime} \in L, \forall s \in S(l), s \in S\left(l^{\prime}\right) \\
t_{s l}^{D}=t_{l}+\sum_{k=1}^{s} T_{l k}^{R}+\sum_{k=1}^{s} T_{l k}^{D w}, \forall l \in L, \forall s \in S(l) \\
t_{s l^{\prime}}^{D}=t_{l^{\prime}}+\sum_{k=1}^{s} T_{l^{\prime} k}^{R}+\sum_{k=1}^{s} T_{l^{\prime} k}^{D w}, \forall l^{\prime} \in L, \forall s \in S\left(l^{\prime}\right) \\
t_{s l}^{A}=t_{l}+\sum_{k=1}^{s} T_{l k}^{R}+\sum_{k=1}^{s-1} T_{l k}^{D w}, \forall l \in L, \forall s \in S(l) \\
t_{s l^{\prime}}^{A}=t_{l^{\prime}}+\sum_{k=1}^{s} T_{l^{\prime} k}^{R}+\sum_{k=1}^{s-1} T_{l^{\prime} k}^{D w}, \forall l^{\prime} \in L, \forall s \in S\left(l^{\prime}\right) \\
n_{s l l^{\prime}}=\left\{\begin{array}{l}
0, t_{s l^{\prime}}^{D}-t_{s l}^{A}-T_{s l l^{\prime}}^{T r a}>=0 \\
c e i l\left(\left|t_{s l^{\prime}}^{D}-t_{s l}^{A}-T_{s l l^{\prime}}^{T r a}\right| / H_{l^{\prime}}\right), \text { otherwise }
\end{array}, \forall l \in L, l^{\prime} \in L, \forall s \in S(l), s \in S\left(l^{\prime}\right)\right. \\
T_{l s}^{D w}, T_{l^{\prime} s}^{D w} \in\left\{T_{\mathrm{int}}^{D w}, T_{\mathrm{tra}}^{D w}\right\}, \forall l \in L, l^{\prime} \in L, \forall s \in S(l), s \in S\left(l^{\prime}\right) \\
T_{l}^{\min } \leq t_{l} \leq T_{l}^{\mathrm{max}}, \forall l \in L \\
T_{l^{\prime}}^{\min } \leq t_{l^{\prime}} \leq T_{l^{\prime}}^{\max }, \forall l^{\prime} \in L
\end{gathered}
$$

There are non-linear constraints (for determining $n_{s l l^{\prime}}$ ) in model M1 that make the model difficult to solve by mixed integer programming (MIP) solvers. Therefore, $\forall l \in L, l^{\prime} \in L, \forall s \in S(l)$, $s \in S\left(l^{\prime}\right)$ above constraints are reformulated as follows.

$$
n_{s l l^{\prime}}=\left\{\begin{array}{l}
0, t_{s l^{\prime}}^{D}-t_{s l}^{A}-T_{s l l^{\prime}}^{T r a} \geq 0 \\
\operatorname{ceil}\left(\left|t_{s l^{\prime}}^{D}-t_{s l}^{A}-T_{s l l^{\prime}}^{T r a}\right| / H_{l^{\prime}}\right), \text { otherwise }
\end{array} \Rightarrow t_{s l^{\prime}}^{D}-t_{s l}^{A}-T_{s l l^{\prime}}^{T r a}+n_{s l l^{\prime}} \cdot H_{l^{\prime}} \geq 0\right.
$$


Remark 2: Constraint $t_{s l^{\prime}}^{D}-t_{s l}^{A}-T_{s l l^{\prime}}^{T r a}+n_{s l l^{\prime}} \cdot H_{l^{\prime}} \geq 0$ can directly capture the correct number of missed trains that have passed through station $s$ in line $l^{\prime}$ when passengers arrive at $s$.

Proof: The network based TWT for passengers can be minimized by the objectives in model M1 (or model M2). Clearly, values of TWT are greater than or equal to zero. Therefore, we have the following Equation (16), which also determines $n_{s l l^{\prime}}$. With the minimization objective of M2, the non-linear constraints can be represented by Equation (16).

$$
t_{s l l^{\prime}}^{T W T}=t_{s l^{\prime}}^{D}-t_{s l}^{A}-T_{s l l^{\prime}}^{T r a}+n_{s l l^{\prime}} \cdot H_{l^{\prime}} \geq 0
$$

As proved previously, to reach the minimum TWT goal while taking passenger volumes into account, model M1 can be reformulated as model M2. The first train timetabling model M2 in Equation (17) aims at minimizing the number of missed trains while considering transfer passengers. On the one hand, M2 can be indirectly understood to minimize the total first train TWT for passengers in a subway network. On the other hand, this model also reduces the number of operating trains, which is important from the viewpoint of railway companies.

Model M2 represents our final MIP model and can be solved directly by any MIP software (e.g., CPLEX) or standard optimization package (e.g., GAMS).

$$
\mathrm{M} 2: N=\min \sum_{s \in S(l) \cap S\left(l^{\prime}\right)} \sum_{l \in L} \sum_{l^{\prime} \in L}\left(\xi_{s l l^{\prime}} \cdot n_{s l l^{\prime}}+\xi_{s l^{\prime} l} \cdot n_{s l^{\prime} l}\right)+\sum_{s \in S(l) \cap S\left(l^{\prime}\right)} \sum_{l \in L} \sum_{l^{\prime} \in L} \psi_{s l l^{\prime}} \cdot\left(t_{s l^{\prime}}^{A}-t_{s l}^{A}\right)
$$

s.t. $\xi_{s l l^{\prime}}=v_{s l l^{\prime}} \cdot H_{l^{\prime}}, \forall l \in L, l^{\prime} \in L, \forall s \in S(l), s \in S\left(l^{\prime}\right)$

$$
\begin{aligned}
& \xi_{s l^{\prime} l}=v_{s l^{\prime}} \cdot H_{l}, \forall l \in L, l^{\prime} \in L, \forall s \in S(l), s \in S\left(l^{\prime}\right) \\
& \psi_{s l l^{\prime}}=v_{s l l^{\prime}}-v_{s l^{\prime} l}, \forall l \in L, l^{\prime} \in L, \forall s \in S(l), s \in S\left(l^{\prime}\right) \\
& t_{s l}^{D}=t_{l}+\sum_{k=1}^{s} T_{l k}^{R}+\sum_{k=1}^{s} T_{l k}^{D w}, \forall l \in L, \forall s \in S(l) \\
& t_{s l^{\prime}}^{D}=t_{l^{\prime}}+\sum_{k=1}^{s} T_{l^{\prime} k}^{R}+\sum_{k=1}^{s} T_{l^{\prime} k}^{D w}, \forall l^{\prime} \in L, \forall s \in S\left(l^{\prime}\right) \\
& t_{s l}^{A}=t_{l}+\sum_{k=1}^{s} T_{l k}^{R}+\sum_{k=1}^{s-1} T_{l k}^{D w}, \forall l \in L, \forall s \in S(l) \\
& t_{s l^{\prime}}^{A}=t_{l^{\prime}}+\sum_{k=1}^{s} T_{l^{\prime} k}^{R}+\sum_{k=1}^{s-1} T_{l^{\prime} k}^{D w}, \forall l^{\prime} \in L, \forall s \in S\left(l^{\prime}\right) \\
& t_{s l^{\prime}}^{D}-t_{s l}^{A}-T_{s l l^{\prime}}^{T r a}+n_{s l l^{\prime}} \cdot H_{l^{\prime}} \geq 0, \forall l \in L, l^{\prime} \in L, \forall s \in S(l), s \in S\left(l^{\prime}\right) \\
& T_{l s}^{D w}, T_{l^{\prime} s}^{D w} \in\left\{T_{\mathrm{int}}^{D w}, T_{\mathrm{tra}}^{D w}\right\}, \forall l \in L, l^{\prime} \in L, \forall s \in S(l), s \in S\left(l^{\prime}\right) \\
& T_{l}^{\text {min }} \leq t_{l} \leq T_{l}^{\max }, \forall l \in L \\
& T_{l^{\prime}}^{\min } \leq t_{l^{\prime}} \leq T_{l^{\prime}}^{\max }, \forall l^{\prime} \in L
\end{aligned}
$$




\section{Solution algorithm and sample tests}

\subsection{Local search heuristic}

The number of integer variables in the above integer programming model is a good index of its complexity. Variable $n_{s l l^{\prime}}$ represents the missed trains between the first train of line $l$ and the first train of line $l^{\prime}$ at station $s$. This means that an integer variable is used for every combination of two first trains on different lines that intersect at $s$. The number of integer variables in the worst case is $O\left(S^{2} L^{2}\right)$, where $S$ denotes the number of transfer stations and $L$ denotes the number of lines in the network. If we want to solve a large network, e.g., the Pairs network or the London metro, it would require much time. This was the motivation for the development of an effective local search algorithm that would solve such problems in a reasonable time due to its scalability.

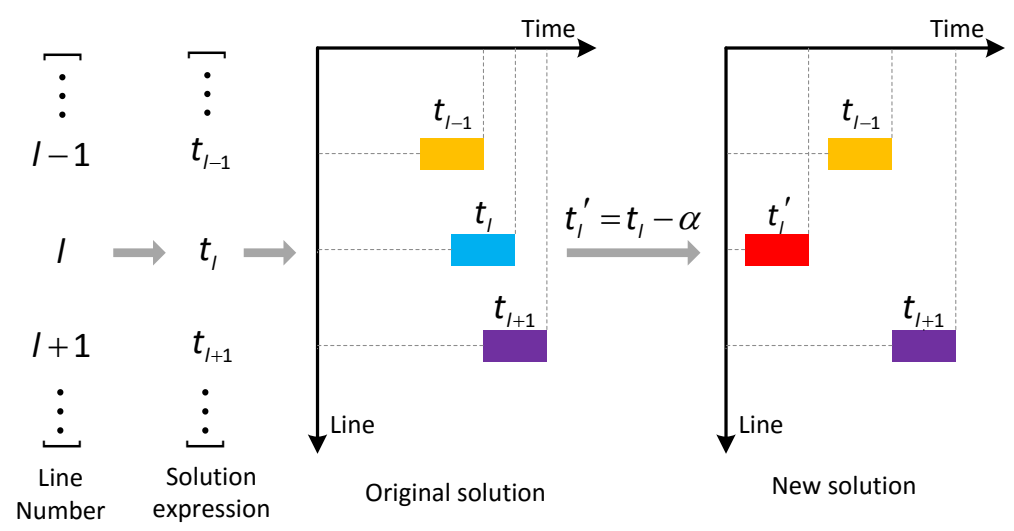

Figure 5 Producing new solutions

The heuristic (Algorithm 1) contains an outer loop to select a sensitive metro line and an inner loop to optimize its departure time. We use $I_{p}$ and $O_{i}$ to record the number of loops that run in the inner and outer loop algorithms, respectively. First, an initial solution $d$ (randomly produced or input) is set as the best solution $d_{b e s t}$. The values of $I_{\max }, O_{\max }, I_{p}$ and $O_{i}$ are initialized. Next, solution $d$ is copied to $d^{\prime}$, and operators in Figure 5 are applied to $d^{\prime}$ to produce new solutions. In Figure 5, each solution is coded in a vector according to line numbers. We select a number $l$ according to Algorithm 2 and take solution operator to $t_{l}$ (one-to-one correspondence). The original departure time $t_{l}$ of line $l$ is replaced by $t_{l}-\alpha$, where parameter $\alpha$ is randomly generated as a mutation factor and is limited with Equation (12). A new solution is created after updating the elements in the vector. Then, we use the methods shown in Figure 6 to make timetables for solutions $d_{\text {best }}$ and $d^{\prime}$. In Figure 6, based on existing running times and dwell times, the (network) first train timetable can be 
produced with constraints $(10-11,13)$ when the line departure times are calculated from the above step. Further, the periodic timetable can also be designed with the proper headway included. According to the above timetables, the corresponding objective functions are calculated. Following that, the algorithm decides whether to accept the new solution or not. After that, the inner loop $I_{p}$ and the out loop $O_{i}$ are updated. Finally, the algorithm stops when the best solution has been found.

Algorithm 1. Local search heuristic

1: Initialize: read running times and dwell times of the original timetable; input initial solutions.

2: $\quad d_{\text {best }} \leftarrow d \leftarrow$ initial $d$.

3: For $O_{i}=1 \ldots O_{\max }$

4: $\quad$ Search for the most sensitive line $l$ using Algorithm 2.

5: $\quad$ For $I_{p}=1 \ldots I_{\max }$

6: $\quad$ Change departure time of line $l, t_{l} \leftarrow t_{l}-\alpha$. // See Figure 5 .

7: $\quad$ Generate new solution from the above step, $d^{\prime} \leftarrow d$.

8: $\quad$ Create timetables for $d^{\prime}$ and $d$ // See Figure 6.

9: $\quad$ If $N\left(d^{\prime}\right)<N(d)$, then // Compare objective values.

10: $\quad d \leftarrow d^{\prime}$;

11: $\quad$ Else if $N(d)-N\left(d^{\prime}\right) \leq \varepsilon$, then // Accept solution if it is a little bit worse.

12: $\quad d \leftarrow d^{\prime}$;

13: $\quad$ End if

14: If $N(d)<N\left(d_{\text {best }}\right)$, then

15: $\quad d_{\text {best }} \leftarrow d$;

16: $\quad$ End if

17: $\quad$ End for

18: End for

19: Return $d_{\text {best }}$. 


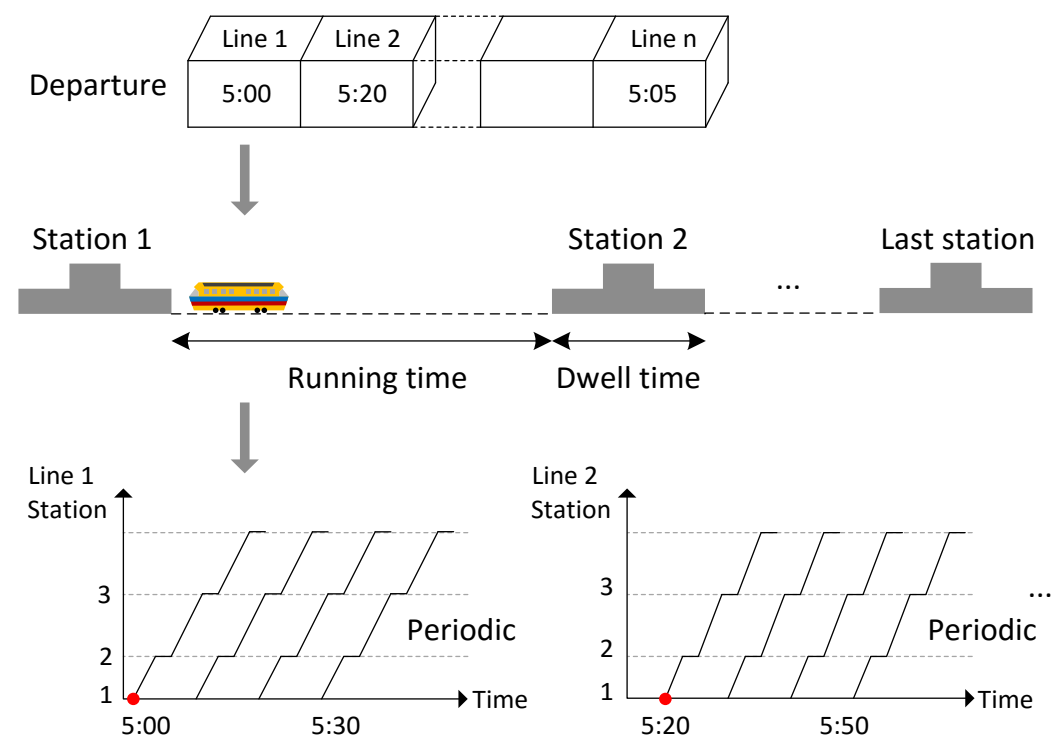

Figure 6 Creating timetables for the first trains

Algorithm 2: Sensitivity test of line departure times in the network. This method selects one of the most sensitive lines (the largest absolute value difference of objective functions between the upper and lower bounds of associated solutions) to search for the local best-case scenario. As Figure 7 shows, the departure time of any line $l$ is limited by $\left[t_{l}-\beta, t_{l}+\beta\right]$, where $\beta$ is given as a parameter. When $\beta$ is small enough, $\left[t_{l}-\beta, t_{l}+\beta\right]$ is considered to be continuous. In this paper, the final proposed first train model is an MIP model. Variables $t_{l}$ are integer variables. Therefore, the value of $\beta$ should be less than one to traverse all possible solutions in the upper and lower ranges.

\section{Algorithm 2. Finding the most sensitive line}

1: $\quad$ For $i=1: m$ ( $m$ represents the total number of subway lines)

2: $\quad$ Change line departure time $\bar{t}_{i}=t_{i}+\beta, \underline{t_{i}}=t_{i}-\beta$.

3: $\quad$ Update the upper and lower departure times in $m \times m$ matrixes $\bar{D}$ and $\underline{D}$.

4: $\quad$ End for

5: With the solutions in matrixes $\bar{D}$ and $\underline{D}$, create timetables according to model (17).

6: $\quad$ Calculate the objective values for the above timetables.

7: $\quad$ Store the objective values in two $m \times 1$ matrixes $(N(\bar{D})$ and $N(\underline{D}))$, Equations (18-19).

8: $\quad$ Select the largest value by $\left|N(\bar{D})_{l}-N(\underline{D})_{l}\right|$ and record the index $l$ (the most sensitive line). 


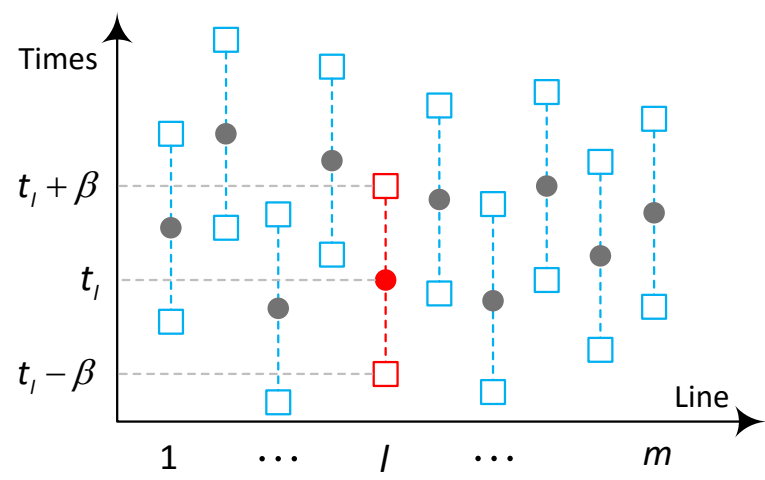

Figure 7 Modifying line departure times

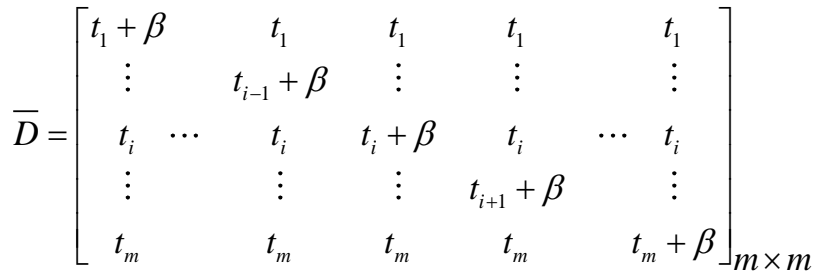

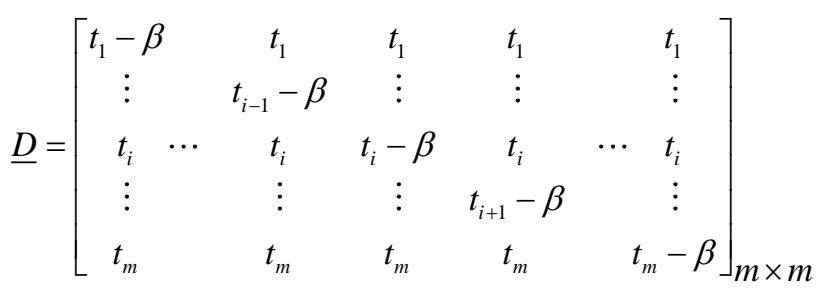

Remark 3: The most sensitive line $l$ in each out loop algorithm of Algorithm 1 is tracked in Equation (20), where $N(\bar{D})_{l}$ and $N(\underline{\mathrm{D}})_{l}$ represent objective values of solutions $\left(t_{1}, \ldots, t_{l}+\beta, \ldots t_{m}\right)$ and $\left(t_{1}, \ldots, t_{l}-\beta, \ldots t_{m}\right)$, respectively.

$$
l=\left\{l|\max | N(\bar{D})_{l}-N(\underline{\mathrm{D}})_{l} \mid, l \in L\right\}
$$

Proof: Line departure time $t_{l}$ is an integer variable. Departure times $t_{l} \pm \beta$ can be considered as neighborhood strings of $t_{l}$. As to points $\left\{t_{l}-\beta, t_{l}, t_{l}+\beta\right\}$, if the function simulated by the objective values of solutions $\left(t_{1}, \ldots, t_{l}+\beta, \ldots t_{m}\right), \quad\left(t_{1}, \ldots, t_{l}, \ldots t_{m}\right)$ and $\left(t_{1}, \ldots, t_{l}-\beta, \ldots t_{m}\right)$ is monotonically increasing or decreasing, we can say that variable $t_{l}$ in this neighborhood rang $\left[t_{l}-\beta, t_{l}+\beta\right]$ has a higher or equal probability than other neighborhood ranges to search for global solutions. This neighborhood range is called linear increasing or decreasing searching area. Therefore, $\forall l \in L$, the most sensitive variable $t_{l}$ has the largest absolute difference of related objective values 
$\left(\left|N(\bar{D})_{l}-N(\underline{\mathrm{D}})_{l}\right|\right)$ in $\left[t_{l}-\beta, t_{l}+\beta\right]$. However, parameter $\beta$ should be limited to as small a number as possible under the condition of reasonable algorithm efficiency.

\subsection{Sample tests}

A sample network with three bi-directional lines crossing at two transfer stations is designed for the numerical tests; see Figure 8 for an illustration. Segment running times between two stations are given along the lines. In addition, the dwell time at any transfer station is set to $1 \min \left(T_{l s}^{D w}=1\right)$; transfer time between two lines is set to $3 \mathrm{~min}\left(T_{s l l^{\prime}}^{\text {Tra }}=3\right)$; the headway time of line 1 is $10 \mathrm{~min}$ $\left(H_{1 \mathrm{U}}=H_{1 \mathrm{D}}=10\right)$; and headways of line 2 and line $3\left(H_{2 \mathrm{U}}=H_{2 \mathrm{D}}=H_{3 \mathrm{U}}=H_{3 \mathrm{D}}=5\right)$ are 5 min. The number of transfer passengers is given in the second column of Table 3. For comparison, each first train starts at 5:00:00 am, and the transfer results of the original timetable are recorded in Table 3. As we can see, there are 20 missed trains in this sample test. First-to-first transfers are only possible for four directions $\left(n_{\text {sll }}=0\right)$. However, 12 connections force passengers to wait for more than one headway time. Among them, four connections in Table 3 have as large as three missed trains, which can also be improved. As for the TWT, passengers wait 1605 min in total with the original timetable.

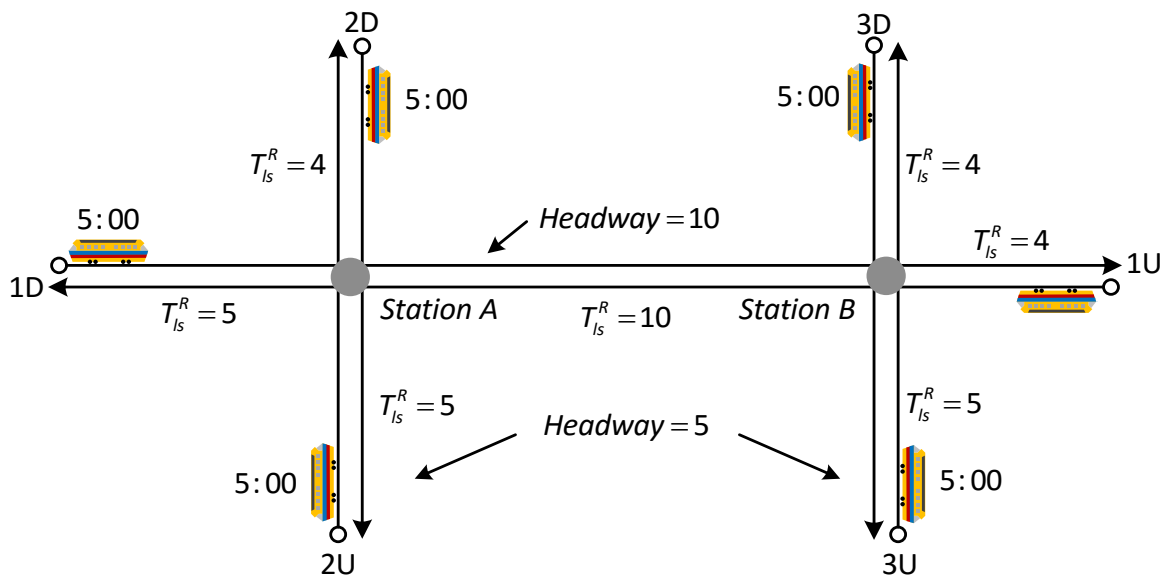

Figure 8 A sample network for numerical tests

Table 3 First train connections of the original timetable

\begin{tabular}{|c|c|c|c|c|c|c|c|c|}
\hline \multirow{2}{*}{ Direction } & \multirow{2}{*}{$v_{s l l^{\prime}}$} & \multicolumn{2}{|c|}{ Feeder Line } & \multirow{2}{*}{ Transfer } & \multicolumn{2}{|c|}{ Connecting Line } & \multirow{2}{*}{$n_{s l l^{\prime}}$} & \multirow{2}{*}{$\begin{array}{l}\text { TWT } \\
(\min )\end{array}$} \\
\hline & & Vehicle Dep. & Arrival & & Vehicle Dep. & Departure & & \\
\hline $1 \mathrm{U}$ to $2 \mathrm{U}$ & 10 & 5:00:00 & $5: 05: 00$ & $3 \mathrm{~min}$ & 5:00:00 & 5:06:00 & 1 & 30 \\
\hline $2 \mathrm{U}$ to $1 \mathrm{U}$ & 30 & 5:00:00 & $5: 05: 00$ & $3 \min$ & 5:00:00 & 5:06:00 & 1 & 240 \\
\hline $1 \mathrm{U}$ to $2 \mathrm{D}$ & 10 & 5:00:00 & $5: 05: 00$ & $3 \mathrm{~min}$ & 5:00:00 & $5: 05: 00$ & 1 & 20 \\
\hline $2 \mathrm{D}$ to $1 \mathrm{U}$ & 10 & 5:00:00 & $5: 04: 00$ & $3 \mathrm{~min}$ & 5:00:00 & 5:06:00 & 1 & 90 \\
\hline
\end{tabular}




\begin{tabular}{|c|c|c|c|c|c|c|c|c|}
\hline 1D to $2 \mathrm{U}$ & 40 & $5: 00: 00$ & $5: 15: 00$ & $3 \mathrm{~min}$ & $5: 00: 00$ & $5: 06: 00$ & 3 & 120 \\
\hline 2U to 1D & 20 & $5: 00: 00$ & $5: 05: 00$ & $3 \mathrm{~min}$ & $5: 00: 00$ & $5: 16: 00$ & 0 & 160 \\
\hline 1D to 2D & 10 & $5: 00: 00$ & $5: 15: 00$ & $3 \mathrm{~min}$ & $5: 00: 00$ & $5: 05: 00$ & 3 & 20 \\
\hline 2D to 1D & 10 & $5: 00: 00$ & $5: 04: 00$ & $3 \mathrm{~min}$ & $5: 00: 00$ & $5: 16: 00$ & 0 & 90 \\
\hline 1U to 3U & 20 & $5: 00: 00$ & $5: 16: 00$ & $3 \mathrm{~min}$ & $5: 00: 00$ & $5: 06: 00$ & 3 & 40 \\
\hline 3U to 1U & 15 & $5: 00: 00$ & $5: 05: 00$ & $3 \mathrm{~min}$ & $5: 00: 00$ & $5: 17: 00$ & 0 & 135 \\
\hline 1U to 3D & 20 & $5: 00: 00$ & $5: 16: 00$ & $3 \mathrm{~min}$ & $5: 00: 00$ & $5: 05: 00$ & 3 & 20 \\
\hline 3D to 1U & 30 & $5: 00: 00$ & $5: 04: 00$ & $3 \mathrm{~min}$ & $5: 00: 00$ & $5: 17: 00$ & 0 & 300 \\
\hline 1D to 3U & 10 & $5: 00: 00$ & $5: 04: 00$ & $3 \mathrm{~min}$ & $5: 00: 00$ & $5: 06: 00$ & 1 & 40 \\
\hline 3U to 1D & 25 & $5: 00: 00$ & $5: 05: 00$ & $3 \mathrm{~min}$ & $5: 00: 00$ & $5: 05: 00$ & 1 & 175 \\
\hline 1D to 3D & 15 & $5: 00: 00$ & $5: 04: 00$ & $3 \mathrm{~min}$ & $5: 00: 00$ & $5: 05: 00$ & 1 & 45 \\
\hline 3D to 1D & 10 & $5: 00: 00$ & $5: 04: 00$ & $3 \mathrm{~min}$ & $5: 00: 00$ & $5: 05: 00$ & 1 & 80 \\
\hline Total & -- & -- & -- & -- & -- & -- & 20 & 1605 \\
\hline
\end{tabular}

The optimal results in Table 4 are found by solving the MIP model, using the heuristic algorithm and the CPLEX. Detailed analyses of optimization results are provided below.

The number of missed trains is reduced from 20 to 8 , an improvement of $60.0 \%$. A common phenomenon in the " $n_{\text {sll' }}$ " column of Table 4 is that there is only one inter-transfer direction at most being synchronized by two first trains. To explain this phenomenon, we take line $1 \mathrm{U}$ and line $2 \mathrm{U}$ crossing at station $A$ in Figure 8 as an example. If both directions are connected by the first trains at station $A$, then we will have Equation (21) and Equation (22). However, Equation (22) is not true because we set $T_{s l l^{\prime}}^{T r a}=T_{s l^{\prime} l}^{T r a}=3$ and $T_{l s}^{D w}=T_{l^{\prime} s}^{D w}=1$ in this test. Therefore, there is only one direction of two inter-transfer directions that can be synchronized by two first trains.

$$
\begin{gathered}
\left\{\begin{array} { c } 
{ t _ { A 2 \mathrm { U } } ^ { D } - t _ { A 1 \mathrm { U } } ^ { A } - T _ { A 1 \mathrm { U } 2 \mathrm { U } } ^ { T r a } \geq 0 } \\
{ t _ { A 1 \mathrm { U } } ^ { D } - t _ { A 2 \mathrm { U } } ^ { A } - T _ { A 2 \mathrm { U } 1 \mathrm { U } } ^ { T r a } \geq 0 }
\end{array} \Leftrightarrow \left\{\begin{array} { l } 
{ t _ { A 2 \mathrm { U } } ^ { A } + T _ { A 2 \mathrm { U } } ^ { D w } \geq t _ { A 1 \mathrm { U } } ^ { A } + T _ { A 1 \mathrm { U } 2 \mathrm { U } } ^ { T r a } } \\
{ t _ { A 1 \mathrm { U } } ^ { A } + T _ { A 1 \mathrm { U } } ^ { D w } \geq t _ { A 2 \mathrm { U } } ^ { A } + T _ { A 2 \mathrm { U } 1 \mathrm { U } } ^ { T r a } }
\end{array} \Leftrightarrow \left\{\begin{array}{l}
T_{A 2}^{D w} \geq t_{A 1 \mathrm{U}}^{A}-t_{A 2 \mathrm{U}}^{A}+T_{A 1 \mathrm{U} 2 \mathrm{U}}^{T r a} \\
T_{A 1}^{D w} \geq t_{A 2 \mathrm{U}}^{A}-t_{A 1 \mathrm{U}}^{A}+T_{A 2 \mathrm{U} 1 \mathrm{U}}^{T r a}
\end{array}\right.\right.\right. \\
T_{A 1 \mathrm{U}}^{D w}+T_{A 2 \mathrm{U}}^{D w} \geq T_{A 2 \mathrm{U} 1 \mathrm{U}}^{T r a}+T_{A 1 \mathrm{U} 2 \mathrm{U}}^{T r a}
\end{gathered}
$$

The total TWT has been reduced from $1605 \mathrm{~min}$ to $345 \mathrm{~min}$, a decrease of $78.5 \%$. As Table 4 shows, passengers can transfer to the FCT $\left(n_{s l l^{\prime}}=0\right)$ or the second train $\left(n_{s l l^{\prime}}=1\right)$ of each line smoothly. In addition, the TWT of each direction is controlled within reasonable limits.

In addition, long waiting times of more than one headway have been completely eliminated. If the first feeder train arrives earlier than the first connecting train for one headway time, then the first feeder passengers will have a long wait. Therefore, the optimal timetable coordinates the arrival/departure times of the first feeder and the connecting trains to reduce the TWT for passengers effectively. 
Table 4 First train connections of the optimal timetable

\begin{tabular}{|c|c|c|c|c|c|c|c|}
\hline \multirow{2}{*}{ Direction } & \multicolumn{2}{|c|}{ Feeder Line } & \multirow{2}{*}{ Transfer } & \multicolumn{2}{|c|}{ Connecting Line } & \multirow{2}{*}{$n_{\text {sll' }}$} & \multirow{2}{*}{ TWT (min) } \\
\cline { 2 - 6 } & Vehicle Dep. & Arrival & & Vehicle Dep. & Departure & & \\
\hline 1U to 2U & $4: 56: 00$ & $5: 01: 00$ & $3 \min$ & $5: 05: 00$ & $5: 10: 00$ & 0 & 60 \\
\hline 2U to 1U & $5: 04: 00$ & $5: 09: 00$ & $3 \min$ & $4: 57: 00$ & $5: 02: 00$ & 1 & 0 \\
\hline 1U to 2D & $4: 56: 00$ & $5: 01: 00$ & $3 \min$ & $5: 06: 00$ & $5: 10: 00$ & 0 & 60 \\
\hline 2D to 1U & $5: 05: 00$ & $5: 09: 00$ & $3 \min$ & $4: 57: 00$ & $5: 02: 00$ & 1 & 0 \\
\hline 1D to 2U & $4: 57: 00$ & $5: 12: 00$ & $3 \min$ & $5: 05: 00$ & $5: 10: 00$ & 1 & 0 \\
\hline 2U to 1D & $5: 04: 00$ & $5: 09: 00$ & $3 \min$ & $4: 58: 00$ & $5: 13: 00$ & 0 & 20 \\
\hline 1D to 2D & $4: 57: 00$ & $5: 12: 00$ & $3 \min$ & $5: 06: 00$ & $5: 10: 00$ & 1 & 0 \\
\hline 2D to 1D & $5: 05: 00$ & $5: 09: 00$ & $3 \min$ & $4: 58: 00$ & $5: 13: 00$ & 0 & 10 \\
\hline 1U to 3U & $4: 56: 00$ & $5: 12: 00$ & $3 \min$ & $5: 05: 00$ & $5: 10: 00$ & 1 & 0 \\
\hline 3U to 1U & $5: 04: 00$ & $5: 09: 00$ & $3 \min$ & $4: 57: 00$ & $5: 13: 00$ & 0 & 15 \\
\hline 1U to 3D & $4: 56: 00$ & $5: 12: 00$ & $3 \min$ & $5: 06: 00$ & $5: 10: 00$ & 1 & 0 \\
\hline 3D to 1U & $5: 05: 00$ & $5: 09: 00$ & $3 \min$ & $4: 57: 00$ & $5: 13: 00$ & 0 & 30 \\
\hline 1D to 3U & $4: 57: 00$ & $5: 01: 00$ & $3 \min$ & $5: 05: 00$ & $5: 10: 00$ & 0 & 60 \\
\hline 3U to 1D & $5: 04: 00$ & $5: 09: 00$ & $3 \min$ & $4: 58: 00$ & $5: 02: 00$ & 1 & 0 \\
\hline 1D to 3D & $4: 57: 00$ & $5: 01: 00$ & $3 \min$ & $5: 06: 00$ & $5: 10: 00$ & 0 & 90 \\
\hline 3D to 1D & $5: 05: 00$ & $5: 09: 00$ & $3 \min$ & $4: 58: 00$ & $5: 02: 00$ & 1 & 0 \\
\hline Total & -- & -- & -- & & -- & 8 & 345 \\
\hline
\end{tabular}

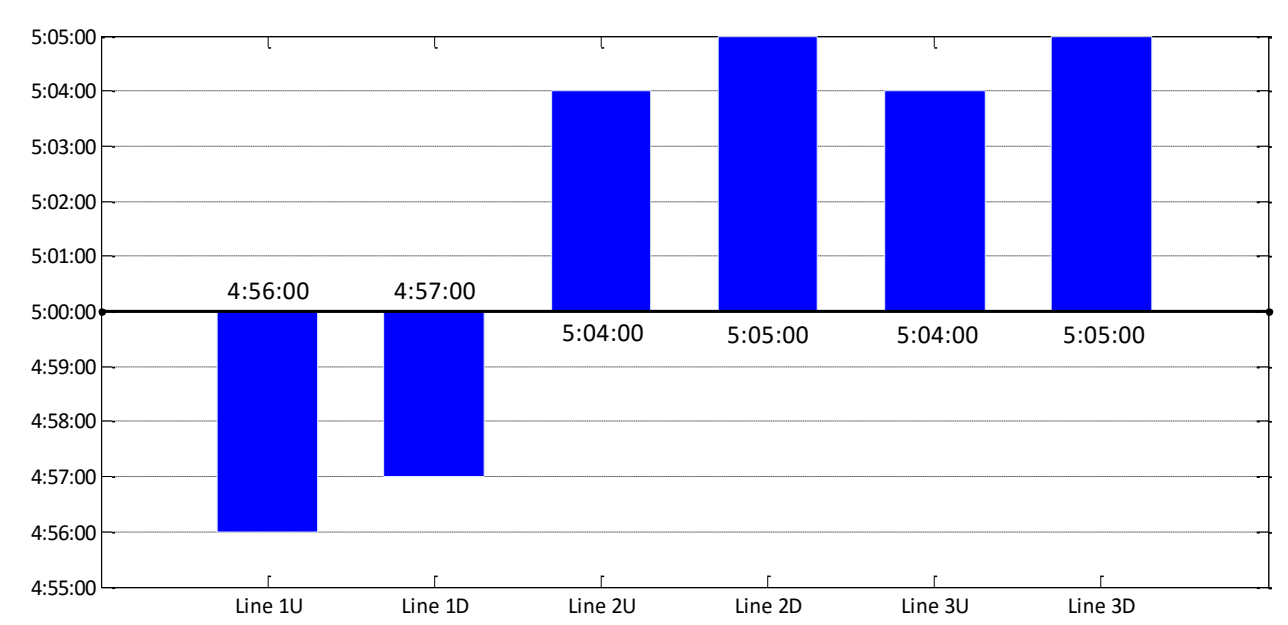

Figure 9 Optimal line departure times of the sample network

Departure time variations of lines can be found in Figure 9. As mentioned before, the original line departure times $\left(t_{l}\right)$ are set to 5:00:00. By changing $t_{l}$ to $t_{l}-\alpha$ where $\alpha$ is limited to $[-5,5]$ min, the six first trains depart from their depots at 4:56:00, 4:57:00, 5:04:00, 5:05:00, 5:04:00 and 5:05:00. The performance of the heuristic algorithm is compared with that of CPLEX. In this small example, the heuristic algorithm takes less than $1 \mathrm{~s}$ and is always able to find the optimal solution, whereas CPLEX takes $18 \mathrm{~s}$ to return a solution. 


\section{Case study}

\subsection{Original Beijing subway timetable}

To evaluate the first train timetabling model, we use a real-life subway network with a number of lines and stations. The network in Figure 10 is the Beijing subway network, which consists of 18 operating lines (9 bi-directional lines) and 31 transfer stations. Each first train departs from one vehicle depot (the square in Figure 10) in a line and terminates at another on the same line. It should be noted that two first trains on each circle loop line (line 2 and line 10) start from the same vehicle depot and travel in opposite directions. Two first trains on line 13 start from XiZhiMen/DongZhiMen stations and terminate at DongZhiMen/XiZhiMen stations.

In this case study, the headways of line 2 , line 10 and line 13 (loop lines) are set to 5 min, line 6 and line 8 are set to $8 \mathrm{~min}$, and the other lines are set to $10 \mathrm{~min}$ according to the Beijing subway schedule. Data on the volumes of first train transfer passengers are provided by the Beijing subway company.

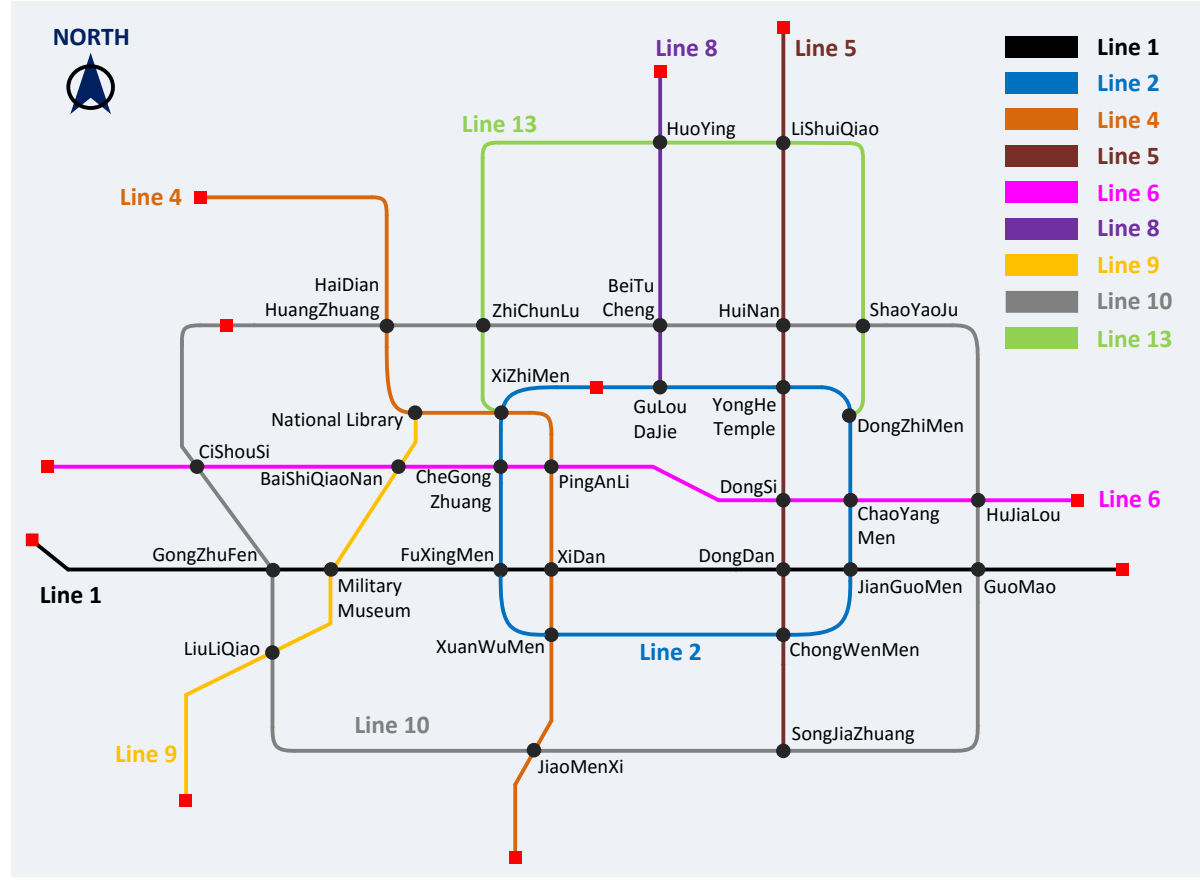

Figure 10 Map of the Beijing Subway

Table $\mathrm{A}$ in the appendix shows the results of missed trains and transfer waiting times of 56 transfer directions for the original Beijing subway system. For space reasons, we only show the data for Line 1. As illustrated, the arrival times of the first feeder trains, the transfer times and the departure times of the first connecting trains are obtained from the published first train timetable. The number of missed trains and the corresponding TWT are calculated and listed in the last two columns of Table A. 


\subsection{Optimal Beijing subway timetable}

The MIP model was solved using CPLEX 12.6.1 on an Intel Core i5 PC with $2.5 \mathrm{GHz}$ and $6 \mathrm{~GB}$ RAM. The optimal first train timetables for the Beijing subway system, which are optimized under departure time constraints ranging from 4:50:00 to 5:10:00, reduce the number of missed trains from 441 to 424 and the total TWT from $22790 \mathrm{~min}$ to $16380 \mathrm{~min}$. The optimization results of the MIP model with respect to line 1 are presented in Table B (see Appendix). In this case, adjusting the arrival and departure times of the first feeder and connecting trains reduced the number of missed trains from 85 to 79 . This results in a total TWT of $6774 \mathrm{~min}$, a decrease of $19.8 \%$ from the original value.

Figure 11 shows the time-distance diagrams of each line at several representative transfer stations in this network. It is unavoidable that some first train transfer passengers will have long wait times in a large subway network due to the network structure, such as at the GongZhuFen station on line 1 and line 10. An effective method to diminish this problem is to stagger line departure times. Another solution is for subway companies to operate half-way trains to eliminate departure time differences.
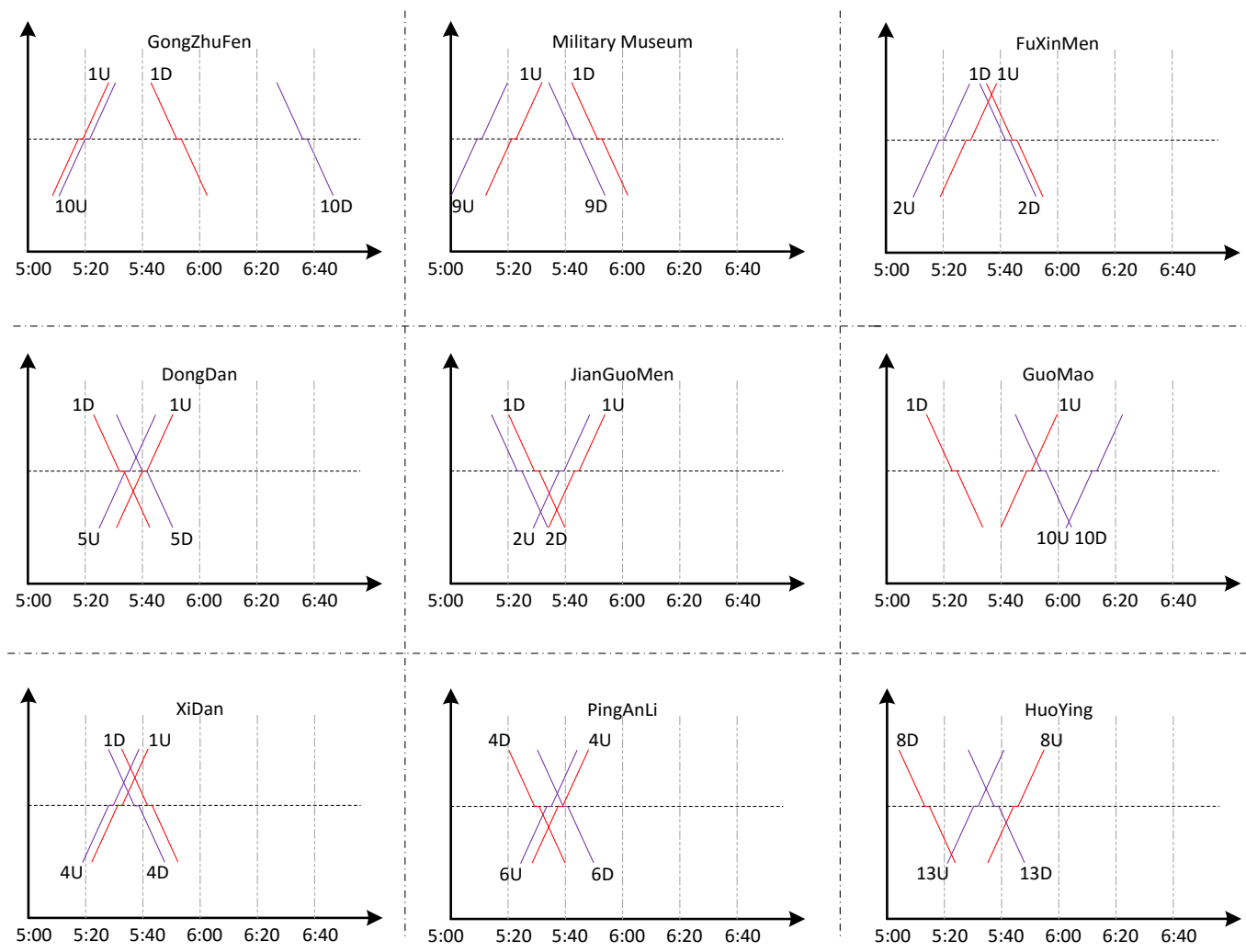

Figure 11 Time-distance diagrams at representative transfer stations

Figure 12 shows the distributions of waiting times for all transfer directions. As illustrated, the optimal timetables increase the number of directions which have less TWT, e.g., TWT in [0,1] min 
and $(1,5]$ min. With respect to long TWT (TWT in $(5,10] \mathrm{min},(10,30] \mathrm{min}$ and $(30,70] \mathrm{min})$, the optimal timetables reduce the number of directions.

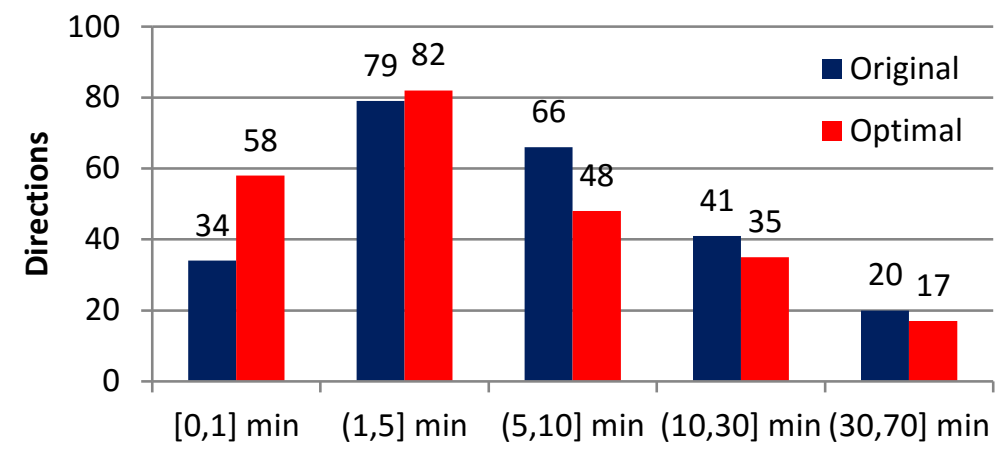

Figure 12 TWT bar chart of two first train timetables for the Beijing subway

\subsection{With and without constraints of first train departure times}

In our proposed first train model, departure times are limited between 4:50:00 and 5:10:00 to ensure that all lines begin operations around the same time. However, it is interesting to test the MIP model without use of Equation (12), which sets constraints on line departure times. Without departure time limits, first trains can start service at any time of the day (theoretically from 00:00 to 24:00).

Table 5 With and without first train departure time limits

\begin{tabular}{|c|c|c|c|c|}
\hline Solution algorithm & Departure time limits & Missed trains & TWT & CPU Time \\
\hline \multirow{2}{*}{ CPLEX } & With Equation (12) & 424 & $16380 \mathrm{~min}$ & $12 \mathrm{~min} 35 \mathrm{~s}$ \\
\cline { 2 - 5 } & Without Equation (12) & 408 & $13550 \mathrm{~min}$ & $58 \mathrm{~min} 12 \mathrm{~s}$ \\
\hline \multirow{2}{*}{ Heuristic } & With Equation (12) & 429 & $16690 \mathrm{~min}$ & $12 \mathrm{~s}$ \\
\cline { 2 - 5 } & Without Equation (12) & 419 & $13972 \mathrm{~min}$ & $14 \mathrm{~s}$ \\
\hline
\end{tabular}

The results in Table 5 compare the above two cases. First, we use the CPLEX to solve the MIP model with first train departure time limits (with Equation 12). As a result, the number of missed trains in the Beijing subway network is 424 and the TWT reaches $16380 \mathrm{~min}$. When solving the model without Equation (12), the number of missed trains is 408 and the TWT is $13550 \mathrm{~min}$. We then use the heuristic to solve the model again. The results show that the number of missed trains is 429 and the TWT is 16690 min when using Equation (12). Meanwhile, the number of missed trains reduces to 419 and the TWT descends to 13972 min when Equation (12) is not applied. In addition, the heuristic only takes approximately $12 \mathrm{~s}$ to run. Therefore, the heuristic has potential to solve even larger networks, such as the London Network, the New York Network and the Tokyo Network.

Regarding the effect of an initial solution, we also tested the heuristic with and without an initial solution. No significant differences in the solutions returned were observed. Therefore, this heuristic 
algorithm can be implemented to solve other timetabling problems and is quite robust because its performance is not influenced by the quality of the initial solution (Barrena et al. 2014).

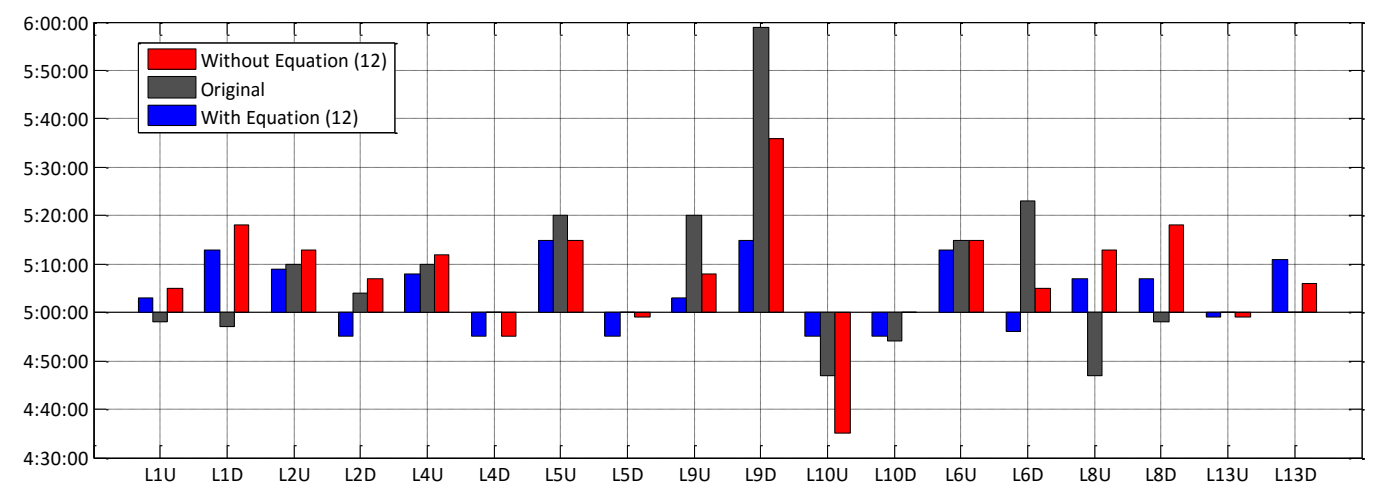

Figure 13 Comparisons of solutions obtained with/without departure time limits

To compare the above two optimal solutions intuitively, a bar chart of different decision variables is provided in Figure 13, where the x-axis shows 18 operating lines and the y-axis represents the first train departure times. As illustrated, most lines have similar departure times with or without the start time limits, with the exception of lines 9D and 10U. Line 9D departs at 5:16:00 with limits and departs at 5:37:00 without limits. Line 10U departs at 4:55:00 with limits and departs at 4:35:00 without limits. These results are also acceptable in real operations. Compared to the original departure times, most lines have similar decisions, with the exception of line 9D, which is due to particular factors that were considered in real operations (low passenger flows in the early morning in line 9D).

\subsection{Effects of train dwell times on TWT}

As Equations (10-11) show, the arrival and departure times are influenced by dwell times. In addition, Equations (21-21) indicate that train dwell times play an important role in timetable synchronization. Therefore, we test the effects of train dwell times on the solutions in Table 6.

Table 6 Analysis of train dwell times

\begin{tabular}{|c|c|c|c|c|c|c|c|}
\hline $\begin{array}{c}\text { Dwell } \\
\text { time }\end{array}$ & $\sum_{s, l, l^{\prime}} n_{s l l^{\prime}}$ & $\sum_{s, l, l^{\prime}} t_{s l^{\prime}}^{T W}$ & {$[0,1] \mathrm{min}$} & $(1,5] \mathrm{min}$ & $(5,10] \mathrm{min}$ & $(10,30] \mathrm{min}$ & $(30,70] \mathrm{min}$ \\
\hline $30 \mathrm{~s}$ & 424 & 16380 & 66 & 79 & 40 & 34 & 21 \\
\hline $60 \mathrm{~s}$ & 424 & 16380 & 58 & 75 & 52 & 35 & 20 \\
\hline $90 \mathrm{~s}$ & 422 & 17150 & 24 & 80 & 76 & 40 & 20 \\
\hline $120 \mathrm{~s}$ & 318 & 17340 & 33 & 73 & 72 & 41 & 21 \\
\hline
\end{tabular}

The case of the 60-s dwell time at transfer stations was selected as the benchmark and results in 424 missed trains with 16380 min of total TWT. The number of transfer directions of TWT within [0,1] $\min ,(1,5] \mathrm{min},(5,10] \mathrm{min}$ and $(10,+\infty] \min$ are 58, 75, 52 and 55, respectively. This 
experiment indicates that large dwell times can reduce missed trains, but they also increase TWT for passengers.

\section{Conclusions}

The problem of first train timetabling considering passenger transfers in a large subway network is an inevitable and challenging optimization problem. Planning departure times of subway lines reasonably can decrease missed trains as well as passenger waiting times at transfer stations. This paper proposes a new approach to precisely describe the first train transfer problem in mathematical terms. Then, non-linear constraints are linearized. Through suitable adjustments of arrival/departure times of feeder/connecting trains, the number of missed trains and passenger waiting times for first train transfers can be minimized. Computational experiments have been carried out on the Beijing subway system based on the original timetables.

Based on research results, there are three general suggestions put forward for the operations and management of urban railway transit. First, headways of the first trains can be reasonably increased to the maximum values. This not only saves operating costs for companies but also reduces the number of missed trains. From the passengers' perspective, transfer waiting times do not increase. In addition, operating strategies such as running interval trains can be applied to large loop lines and long distance lines to decrease waiting times for first train transfers. Taking Beijing subway line 10 for instance, the whole trip time is 133 min. With interval trains, the long waiting times listed in Table 1 can be avoided effectively. Finally, the use of two or more vehicle depots could significantly help to reduce transfer waiting times. They can be located on the diagonals of loop lines or in the middle of straight lines.

The model proposed can be expanded in several ways. For example, lines, transfer stations and directions can be defined with weights, which would make it a weighted optimization problem. In this paper, we assign passengers to different transfer directions to make the model more practical. In addition, the first train timetabling model could be extended to a more comprehensive period-based timetabling model for all the transition periods, from the first train to the morning peak hours. In this way, train intervals of each line can be reduced gradually through inserting additional trains according to the increase in transportation demands. Other methods such as stochastic theory and real-time dispatching can also be considered for further study.

\section{Acknowledgements}


This paper is supported by the China National Funds for Distinguished Young Scientists (No. 71525002), the NSFC (No.71473259, No.71322102). The authors thank the editor (Prof. Hai Yang) and the referees for their meticulous review and their valuable suggestions, which greatly improved this paper. In addition, this work has been partially financed by the Austrian Federal Ministry of Science, Research and Economy (BMWFW) within the EURASIA PACIFIC UNINET scholarship framework.

\section{References}

[1] Barrena, E., Canca, D., Coelho, L.C., Laporte, G., 2014. Single-line rail rapid transit timetabling under dynamic passenger demand. Transportation Research Part B 70, 134-150.

[2] Cacchiani, V., Furinib, F., Kidda, M.P., 2016. Approaches to a real-world train timetabling problem in a railway node. Omega 58, 97-110.

[3] Cacchiani, V., Huisman, D., Kidd, M., Kroon, L., Toth, P., Veelenturf, L., Wagenaar, J., 2014. An overview of recovery models and algorithms for real-time railway rescheduling. Transportation Research Part B 63, 15-37.

[4] Cacchiani, V., Toth, P., 2012. Nominal and robust train timetabling problems. European Journal of Operational Research 219(3), 727-737.

[5] Caprara, A., Fischetti, M., Toth, P., 2002. Modeling and solving the train timetabling problem. Operation Research 50(5), 851-861.

[6] Ceder, A., Golany, B., Tol, O., 2001. Creating bus timetables with maximal synchronization. Transportation Research Part A 35, 913-928.

[7] Chevrier, R., Pellgrini, P., Rodriguez, J., 2013. Energy saving in railway timetabling: A bi-objective evolutionary approach for computing alternative running times. Transportation Research Part C 37, 20-41.

[8] Cordeau, J.F., Toth, P., Vigo, D., 1998. A survey of optimization models for train routing and scheduling. Transportation Science 32(4), 380-404.

[9] Fischetti, M., Salvagnin, D., Zanette, A., 2009. Fast approaches to improve the robustness of a railway timetable. Transportation Science 43(3), 321-335.

[10] Guihaire, V., Hao, J.K., 2008. Transit network design and scheduling: A global review. Transportation Research Part A 42, 1251-1273.

[11] Ibarra-Rojas, O.J., Giesen, R., Rios-Solis, Y.A., 2014. An integrated approach for timetabling and vehicle scheduling problems to analyze the trade-off between level of service and operating coasts of transit networks. Transportation Research Part B 70, 35-46.

[12] Ibarra-Rojas, O.J., Rios-Solis, Y.A., 2012. Synchronization of bus timetabling. Transportation Research Part B 46, 599-614.

[13] Kang, L.J., Wu, J.J., Sun, H.J., Zhu, X.N., Gao, Z.Y., 2015a. A case study on the coordination of last trains for the Beijing subway network. Transportation Research Part B 72, 112-127.

[14] Kang, L.J., Wu, J.J., Sun, H.J., Zhu, X.N., Wang, B., 2015b. A practical model for last train rescheduling with train delay in urban railway transit networks. Omega 50, 29-42.

[15] Lamorgese, L., Mannino, C., Piacentini, M., 2016. Optimal train dispatching by Benders'-like reformulation. Transportation Science, http://dx.doi.org/10.1287/trsc.2015.0605.

[16] Li, X. Lo, H.K., 2014. An energy-efficient scheduling and speed control approach for metro rail 
operations. Transportation Research Part B 64, 73-89.

[17] Liebchen, C., 2008. The first optimized railway timetable in practice. Transportation Science 42 (4), 420-435.

[18] Liebchen, C., Schachtebeck, M., Schöbel, A., Stiller, S., Prigge, A., 2010. Computing delay resistant railway timetables. Computers \& Operations Research 37 (5), 857-868.

[19] Lin, D.Y., Ku, Y.H., 2014. Using genetic algorithms to optimize stopping patterns for passenger rail transportation. Computer-Aided Civil and Infrastructure Engineering 29(4), 264-278.

[20] Liu, Z., Yan, Y., Qu, X., Zhang, Y., 2013. Bus stop-skipping scheme with random travel time. Transportation Research Part C 35, 46-56.

[21] Niu, H., Zhou, X., 2013. Optimizing urban rail timetable under time-dependent demand and oversaturated conditions. Transportation Research Part C 36, 212-230.

[22] Niu, H., Zhou, X., Gao, R., 2015. Train scheduling for minimizing passenger waiting time with time-dependent demand and skip-stop pattern: nonlinear integer programming models with linear constraints. Transportation Research Part B 76, 117-135.

[23] Pellegrini, P., Marliere, G., Rodriguez, J., 2014. Optimal train routing and scheduling for managing traffic perturbations in complex junctions. Transportation Research Part B 59, 58-80.

[24] Shafhi, Y., Khani, A., 2010. A practical model for transfer optimization in a transit network: model formulations and solutions. Transportation Research Part A 44, 377-389.

[25] Wong, R.C.W., Yuen, T.W.Y., Fung, K.W., Leung, J.M.Y., 2008. Optimizing timetable synchronization for rail mass transit. Transportation Science 42(1), 57-69.

[26] Wu, J., Liu, M., Sun, H., Li, T., Gao, Z., Wang, D., 2015. Equity-based timetable synchronization optimization in urban subway network. Transportation Research Part C 51, 1-18.

[27] Yang, X., Chen, A., Ning, B., Tang, T., 2016. A stochastic model for the integrated optimization on metro timetable and speed profile with uncertain train mass. Transportation Research Part B 91, 424-445.

[28] Yin, J., Tang, T., Yang L., Gao, Z., Ran B., 2016. Energy-efficient metro train rescheduling with uncertain time-variant passenger demands: An approximate dynamic programming approach. Transportation Research Part B 91, 178-210. 


\section{Appendix}

Table A. Original first-train connections of Line 1 of the Beijing Subway

\begin{tabular}{|c|c|c|c|c|c|c|c|}
\hline Station & Direction & $v_{s l l^{\prime}}$ & $\begin{array}{c}\text { First Feeder } \\
\text { Train Arr. }\end{array}$ & Transfer & $\begin{array}{c}\text { First Connecting } \\
\text { Train Dep. }\end{array}$ & $n_{s l l^{\prime}}$ & $t_{s l l^{\prime}}^{T W T}$ \\
\hline \multirow{8}{*}{ 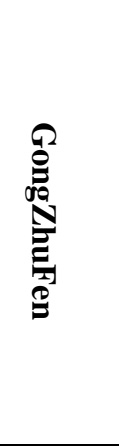 } & $\mathrm{L} 1 \mathrm{U} \rightarrow \mathrm{L} 10 \mathrm{U}$ & 16 & $5: 17: 00$ & $3 \mathrm{~min}$ & $5: 21: 00$ & 0 & 0:01:00 \\
\hline & $\mathrm{L} 10 \mathrm{U} \rightarrow \mathrm{L} 1 \mathrm{U}$ & 9 & $5: 20: 00$ & $3 \mathrm{~min}$ & $5: 18: 00$ & 1 & 0:05:00 \\
\hline & $\mathrm{L} 1 \mathrm{U} \rightarrow \mathrm{L} 10 \mathrm{D}$ & 15 & $5: 17: 00$ & $3 \mathrm{~min}$ & $6: 30: 00$ & 0 & 1:10:00 \\
\hline & $\mathrm{L} 10 \mathrm{D} \rightarrow \mathrm{L} 1 \mathrm{U}$ & 20 & $6: 29: 00$ & $3 \mathrm{~min}$ & 5:18:00 & 8 & 0:06:00 \\
\hline & $\mathrm{L} 1 \mathrm{D} \rightarrow \mathrm{L} 10 \mathrm{U}$ & 14 & $5: 36: 00$ & $3 \mathrm{~min}$ & $5: 21: 00$ & 4 & 0:02:00 \\
\hline & $\mathrm{L} 10 \mathrm{U} \rightarrow \mathrm{L} 1 \mathrm{D}$ & 5 & $5: 20: 00$ & $3 \min$ & $5: 37: 00$ & 0 & 0:14:00 \\
\hline & $\mathrm{L} 1 \mathrm{D} \rightarrow \mathrm{L} 10 \mathrm{D}$ & 7 & $5: 36: 00$ & $3 \mathrm{~min}$ & 6:30:00 & 0 & 0:51:00 \\
\hline & $\mathrm{L} 10 \mathrm{D} \rightarrow \mathrm{L} 1 \mathrm{D}$ & 8 & $6: 29: 00$ & $3 \min$ & $5: 37: 00$ & 6 & 0:05:00 \\
\hline \multirow{8}{*}{ 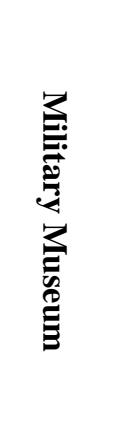 } & $\mathrm{L} 1 \mathrm{U} \rightarrow \mathrm{L} 9 \mathrm{U}$ & 4 & $5: 20: 00$ & $3 \min$ & $5: 10: 00$ & 2 & 0:07:00 \\
\hline & $\mathrm{L} 9 \mathrm{U} \rightarrow \mathrm{L} 1 \mathrm{U}$ & 20 & 5:09:00 & $3 \mathrm{~min}$ & $5: 21: 00$ & 0 & 0:09:00 \\
\hline & $\mathrm{L} 1 \mathrm{U} \rightarrow \mathrm{L} 9 \mathrm{D}$ & 3 & $5: 20: 00$ & $3 \mathrm{~min}$ & $5: 24: 00$ & 0 & 0:01:00 \\
\hline & $\mathrm{L} 9 \mathrm{D} \rightarrow \mathrm{L} 1 \mathrm{U}$ & 1 & $5: 23: 00$ & $3 \mathrm{~min}$ & $5: 21: 00$ & 1 & 0:05:00 \\
\hline & $\mathrm{L} 1 \mathrm{D} \rightarrow \mathrm{L9U}$ & 3 & $5: 33: 00$ & $3 \min$ & $5: 10: 00$ & 3 & 0:04:00 \\
\hline & $\mathrm{L} 9 \mathrm{U} \rightarrow \mathrm{L} 1 \mathrm{D}$ & 18 & 5:09:00 & $3 \mathrm{~min}$ & $5: 34: 00$ & 0 & 0:22:00 \\
\hline & $\mathrm{L} 1 \mathrm{D} \rightarrow \mathrm{L9D}$ & 20 & $5: 33: 00$ & $3 \mathrm{~min}$ & $5: 24: 00$ & 2 & 0:08:00 \\
\hline & $\mathrm{L9D} \rightarrow \mathrm{L} 1 \mathrm{D}$ & 2 & 5:23:00 & $3 \mathrm{~min}$ & $5: 34: 00$ & 0 & 0:08:00 \\
\hline \multirow{8}{*}{ 苞 } & $\mathrm{L} 1 \mathrm{U} \rightarrow \mathrm{L} 2 \mathrm{U}$ & 20 & $5: 27: 00$ & $1.5 \mathrm{~min}$ & $5: 13: 00$ & 4 & $0: 04: 30$ \\
\hline & $\mathrm{L} 2 \mathrm{U} \rightarrow \mathrm{L} 1 \mathrm{U}$ & 16 & 5:12:00 & $1.5 \mathrm{~min}$ & 5:28:00 & 0 & $0: 14: 30$ \\
\hline & $\mathrm{L} 1 \mathrm{U} \rightarrow \mathrm{L} 2 \mathrm{D}$ & 20 & $5: 27: 00$ & $1.5 \mathrm{~min}$ & $5: 41: 00$ & 0 & $0: 12: 30$ \\
\hline & $\mathrm{L} 2 \mathrm{D} \rightarrow \mathrm{L} 1 \mathrm{U}$ & 3 & 5:40:00 & $1.5 \mathrm{~min}$ & $5: 28: 00$ & 2 & 0:06:30 \\
\hline & $\mathrm{L} 1 \mathrm{D} \rightarrow \mathrm{L} 2 \mathrm{U}$ & 1 & $5: 26: 00$ & $1.5 \mathrm{~min}$ & $5: 13: 00$ & 3 & 0:00:30 \\
\hline & $\mathrm{L} 2 \mathrm{U} \rightarrow \mathrm{L} 1 \mathrm{D}$ & 14 & $5: 12: 00$ & $1.5 \mathrm{~min}$ & $5: 27: 00$ & 0 & $0: 13: 30$ \\
\hline & $\mathrm{L} 1 \mathrm{D} \rightarrow \mathrm{L} 2 \mathrm{D}$ & 9 & $5: 26: 00$ & $1.5 \mathrm{~min}$ & $5: 41: 00$ & 0 & $0: 13: 30$ \\
\hline & $\mathrm{L} 2 \mathrm{D} \rightarrow \mathrm{L} 1 \mathrm{D}$ & 20 & $5: 40: 00$ & $1.5 \mathrm{~min}$ & $5: 27: 00$ & 2 & 0:05:30 \\
\hline \multirow{8}{*}{$\begin{array}{l}\text { : } \\
\text { : }\end{array}$} & $\mathrm{L} 1 \mathrm{U} \rightarrow \mathrm{L} 4 \mathrm{U}$ & 2 & $5: 30: 00$ & $5 \min$ & $5: 18: 00$ & 2 & 0:03:00 \\
\hline & $\mathrm{L} 4 \mathrm{U} \rightarrow \mathrm{L} 1 \mathrm{U}$ & 8 & $5: 17: 00$ & $5 \mathrm{~min}$ & $5: 31: 00$ & 0 & 0:09:00 \\
\hline & $\mathrm{L} 1 \mathrm{U} \rightarrow \mathrm{L} 4 \mathrm{D}$ & 9 & 5:30:00 & $5 \mathrm{~min}$ & $5: 37: 00$ & 0 & 0:02:00 \\
\hline & $\mathrm{L} 4 \mathrm{D} \rightarrow \mathrm{L} 1 \mathrm{U}$ & 7 & $5: 36: 00$ & $5 \mathrm{~min}$ & $5: 31: 00$ & 1 & 0:00:00 \\
\hline & $\mathrm{L} 1 \mathrm{D} \rightarrow \mathrm{L} 4 \mathrm{U}$ & 14 & $5: 23: 00$ & $5 \mathrm{~min}$ & 5:18:00 & 1 & 0:00:00 \\
\hline & $\mathrm{L} 4 \mathrm{U} \rightarrow \mathrm{L} 1 \mathrm{D}$ & 4 & $5: 17: 00$ & $5 \mathrm{~min}$ & $5: 24: 00$ & 0 & 0:02:00 \\
\hline & $\mathrm{L} 1 \mathrm{D} \rightarrow \mathrm{L} 4 \mathrm{D}$ & 13 & $5: 23: 00$ & $5 \mathrm{~min}$ & $5: 37: 00$ & 0 & 0:09:00 \\
\hline & $\mathrm{L} 4 \mathrm{D} \rightarrow \mathrm{L} 1 \mathrm{D}$ & 1 & $5: 36: 00$ & $5 \mathrm{~min}$ & $5: 24: 00$ & 2 & 0:03:00 \\
\hline \multirow{6}{*}{ 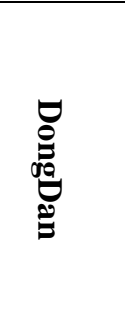 } & $\mathrm{L} 1 \mathrm{U} \rightarrow \mathrm{L} 5 \mathrm{U}$ & 10 & 5:39:00 & $3 \mathrm{~min}$ & 5:15:00 & 3 & 0:03:00 \\
\hline & $\mathrm{L} 5 \mathrm{U} \rightarrow \mathrm{L} 1 \mathrm{U}$ & 8 & $5: 14: 00$ & $3 \min$ & 5:40:00 & 0 & 0:23:00 \\
\hline & $\mathrm{L} 1 \mathrm{U} \rightarrow \mathrm{L} 5 \mathrm{D}$ & 6 & 5:39:00 & $3 \mathrm{~min}$ & $5: 41: 00$ & 1 & 0:09:00 \\
\hline & $\mathrm{L} 5 \mathrm{D} \rightarrow \mathrm{L} 1 \mathrm{U}$ & 6 & $5: 40: 00$ & $3 \mathrm{~min}$ & $5: 40: 00$ & 1 & 0:07:00 \\
\hline & $\mathrm{L} 1 \mathrm{D} \rightarrow \mathrm{L} 5 \mathrm{U}$ & 12 & 5:14:00 & $3 \mathrm{~min}$ & $5: 15: 00$ & 1 & 0:08:00 \\
\hline & $\mathrm{L} 5 \mathrm{U} \rightarrow \mathrm{L} 1 \mathrm{D}$ & 10 & $5: 14: 00$ & $3 \mathrm{~min}$ & $5: 15: 00$ & 1 & 0:08:00 \\
\hline
\end{tabular}




\begin{tabular}{|c|c|c|c|c|c|c|c|}
\hline & $\mathrm{L} 1 \mathrm{D} \rightarrow \mathrm{L} 5 \mathrm{D}$ & 7 & $5: 14: 00$ & $3 \min$ & $5: 41: 00$ & 0 & 0:24:00 \\
\hline & $\mathrm{L} 5 \mathrm{D} \rightarrow \mathrm{L} 1 \mathrm{D}$ & 16 & 5:40:00 & $3 \min$ & $5: 15: 00$ & 3 & 0:02:00 \\
\hline \multirow{8}{*}{ 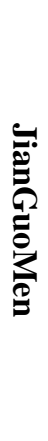 } & $\mathrm{L} 1 \mathrm{U} \rightarrow \mathrm{L} 2 \mathrm{U}$ & 11 & 5:42:00 & $1.5 \mathrm{~min}$ & 5:32:00 & 3 & 0:03:30 \\
\hline & $\mathrm{L} 2 \mathrm{U} \rightarrow \mathrm{L} 1 \mathrm{U}$ & 20 & 5:31:00 & $1.5 \mathrm{~min}$ & 5:43:00 & 0 & $0: 10: 30$ \\
\hline & $\mathrm{L} 1 \mathrm{U} \rightarrow \mathrm{L} 2 \mathrm{D}$ & 5 & 5:42:00 & $1.5 \mathrm{~min}$ & 5:22:00 & 5 & 0:03:30 \\
\hline & $\mathrm{L} 2 \mathrm{D} \rightarrow \mathrm{L} 1 \mathrm{U}$ & 16 & $5: 21: 00$ & $1.5 \mathrm{~min}$ & 5:43:00 & 0 & 0:20:30 \\
\hline & $\mathrm{L} 1 \mathrm{D} \rightarrow \mathrm{L} 2 \mathrm{U}$ & 20 & 5:11:00 & $1.5 \mathrm{~min}$ & 5:32:00 & 0 & 0:19:30 \\
\hline & $\mathrm{L} 2 \mathrm{U} \rightarrow \mathrm{L} 1 \mathrm{D}$ & 20 & 5:31:00 & $1.5 \mathrm{~min}$ & 5:12:00 & 3 & 0:09:30 \\
\hline & $\mathrm{L} 1 \mathrm{D} \rightarrow \mathrm{L} 2 \mathrm{D}$ & 20 & 5:11:00 & $1.5 \mathrm{~min}$ & 5:22:00 & 0 & 0:09:30 \\
\hline & $\mathrm{L} 2 \mathrm{D} \rightarrow \mathrm{L} 1 \mathrm{D}$ & 13 & 5:21:00 & $1.5 \mathrm{~min}$ & 5:12:00 & 2 & 0:09:30 \\
\hline \multirow{8}{*}{ 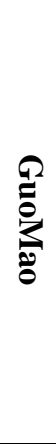 } & $\mathrm{L} 1 \mathrm{U} \rightarrow \mathrm{L} 10 \mathrm{U}$ & 15 & 5:48:00 & $4.5 \mathrm{~min}$ & 6:13:00 & 0 & 0:20:30 \\
\hline & $\mathrm{L} 10 \mathrm{U} \rightarrow \mathrm{L} 1 \mathrm{U}$ & 11 & 6:12:00 & $4.5 \mathrm{~min}$ & 5:49:00 & 3 & 0:02:30 \\
\hline & $\mathrm{L} 1 \mathrm{U} \rightarrow \mathrm{L} 10 \mathrm{D}$ & 20 & 5:48:00 & $4.5 \mathrm{~min}$ & 5:48:00 & 1 & 0:00:30 \\
\hline & $\mathrm{L} 10 \mathrm{D} \rightarrow \mathrm{L} 1 \mathrm{U}$ & 10 & 5:47:00 & $4.5 \mathrm{~min}$ & 5:49:00 & 1 & 0:07:30 \\
\hline & $\mathrm{L} 1 \mathrm{D} \rightarrow \mathrm{L} 10 \mathrm{U}$ & 20 & 5:05:00 & $4.5 \mathrm{~min}$ & 6:13:00 & 0 & 1:03:30 \\
\hline & $\mathrm{L} 10 \mathrm{U} \rightarrow \mathrm{L} 1 \mathrm{D}$ & 19 & 6:12:00 & $4.5 \mathrm{~min}$ & 5:06:00 & 8 & 0:09:30 \\
\hline & $\mathrm{L} 1 \mathrm{D} \rightarrow \mathrm{L} 10 \mathrm{D}$ & 15 & 5:05:00 & $4.5 \mathrm{~min}$ & 5:48:00 & 0 & 0:38:30 \\
\hline & L10D $\rightarrow$ L1D & 14 & $5: 47: 00$ & $4.5 \mathrm{~min}$ & 5:06:00 & 5 & 0:04:30 \\
\hline \multicolumn{5}{|c|}{ Transfer stations of line 1} & $\sum v_{s l l} \cdot t_{s l l^{T}}^{T W T}$ & 85 & $8447 \mathrm{~min}$ \\
\hline \multicolumn{5}{|c|}{ All transfer stations in the network } & $\sum v_{s l l} \cdot t_{s l l^{\prime}}^{T W T}$ & 441 & $22790 \mathrm{~min}$ \\
\hline
\end{tabular}


Table B. Optimal first-train connections in Line 1 of the Beijing Subway

\begin{tabular}{|c|c|c|c|c|c|c|c|}
\hline Station & Direction & $v_{s l l^{\prime}}$ & $\begin{array}{c}\text { First Feeder } \\
\text { Train Arr. }\end{array}$ & Transfer & $\begin{array}{c}\text { First Connecting } \\
\text { Train Dep. }\end{array}$ & $n_{s l l^{\prime}}$ & $t_{s l l^{\prime}}^{T W T}$ \\
\hline \multirow{8}{*}{ 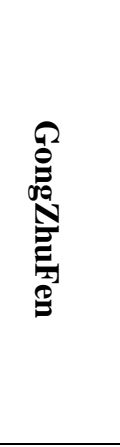 } & $\mathrm{L} 1 \mathrm{U} \rightarrow \mathrm{L} 10 \mathrm{U}$ & 16 & 5:18:00 & $3 \mathrm{~min}$ & $5: 21: 00$ & 0 & 0:00:00 \\
\hline & $\mathrm{L} 10 \mathrm{U} \rightarrow \mathrm{L} 1 \mathrm{U}$ & 9 & $5: 20: 00$ & $3 \min$ & 5:19:00 & 1 & 0:01:00 \\
\hline & $\mathrm{L} 1 \mathrm{U} \rightarrow \mathrm{L} 10 \mathrm{D}$ & 15 & $5: 18: 00$ & $3 \mathrm{~min}$ & $6: 37: 00$ & 0 & 1:16:00 \\
\hline & $\mathrm{L} 10 \mathrm{D} \rightarrow \mathrm{L} 1 \mathrm{U}$ & 20 & $6: 36: 00$ & $3 \mathrm{~min}$ & $5: 19: 00$ & 8 & 0:00:00 \\
\hline & $\mathrm{L} 1 \mathrm{D} \rightarrow \mathrm{L} 10 \mathrm{U}$ & 14 & 5:54:00 & $3 \mathrm{~min}$ & $5: 21: 00$ & 8 & 0:04:00 \\
\hline & $\mathrm{L} 10 \mathrm{U} \rightarrow \mathrm{L} 1 \mathrm{D}$ & 5 & 5:20:00 & $3 \min$ & $5: 55: 00$ & 0 & 0:32:00 \\
\hline & $\mathrm{L} 1 \mathrm{D} \rightarrow \mathrm{L} 10 \mathrm{D}$ & 7 & $5: 54: 00$ & $3 \mathrm{~min}$ & $6: 37: 00$ & 0 & 0:40:00 \\
\hline & $\mathrm{L} 10 \mathrm{D} \rightarrow \mathrm{L} 1 \mathrm{D}$ & 8 & $6: 36: 00$ & $3 \mathrm{~min}$ & $5: 55: 00$ & 5 & 0:06:00 \\
\hline \multirow{8}{*}{ 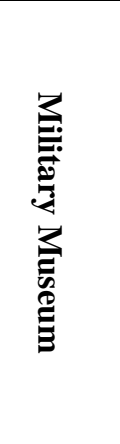 } & $\mathrm{L} 1 \mathrm{U} \rightarrow \mathrm{L9U}$ & 4 & 5:21:00 & $3 \mathrm{~min}$ & 5:10:00 & 2 & 0:06:00 \\
\hline & $\mathrm{L9U} \rightarrow \mathrm{L} 1 \mathrm{U}$ & 20 & 5:09:00 & $3 \mathrm{~min}$ & $5: 22: 00$ & 0 & 0:10:00 \\
\hline & $\mathrm{L} 1 \mathrm{U} \rightarrow \mathrm{L} 9 \mathrm{D}$ & 3 & 5:21:00 & $3 \mathrm{~min}$ & $5: 44: 00$ & 0 & 0:20:00 \\
\hline & $\mathrm{L9D} \rightarrow \mathrm{L} 1 \mathrm{U}$ & 1 & 5:43:00 & $3 \mathrm{~min}$ & 5:22:00 & 3 & 0:06:00 \\
\hline & $\mathrm{L} 1 \mathrm{D} \rightarrow \mathrm{L9U}$ & 3 & 5:51:00 & $3 \min$ & 5:10:00 & 5 & 0:06:00 \\
\hline & $\mathrm{L9U} \rightarrow \mathrm{L1D}$ & 18 & 5:09:00 & $3 \mathrm{~min}$ & 5:52:00 & 0 & 0:40:00 \\
\hline & $\mathrm{L1D} \rightarrow \mathrm{L9D}$ & 20 & $5: 51: 00$ & $3 \min$ & $5: 44: 00$ & 1 & 0:00:00 \\
\hline & $\mathrm{L9D} \rightarrow \mathrm{L} 1 \mathrm{D}$ & 2 & 5:43:00 & $3 \min$ & $5: 52: 00$ & 0 & 0:06:00 \\
\hline \multirow{8}{*}{ 㿣 } & $\mathrm{L} 1 \mathrm{U} \rightarrow \mathrm{L} 2 \mathrm{U}$ & 20 & 5:28:00 & $1.5 \mathrm{~min}$ & 5:20:00 & 2 & 0:00:30 \\
\hline & $\mathrm{L} 2 \mathrm{U} \rightarrow \mathrm{L} 1 \mathrm{U}$ & 16 & $5: 19: 00$ & $1.5 \mathrm{~min}$ & 5:29:00 & 0 & 0:08:30 \\
\hline & $\mathrm{L} 1 \mathrm{U} \rightarrow \mathrm{L} 2 \mathrm{D}$ & 20 & $5: 28: 00$ & $1.5 \mathrm{~min}$ & $5: 43: 00$ & 0 & $0: 13: 30$ \\
\hline & $\mathrm{L} 2 \mathrm{D} \rightarrow \mathrm{L} 1 \mathrm{U}$ & 3 & 5:42:00 & $1.5 \mathrm{~min}$ & 5:29:00 & 2 & 0:05:30 \\
\hline & $\mathrm{L} 1 \mathrm{D} \rightarrow \mathrm{L} 2 \mathrm{U}$ & 1 & 5:44:00 & $1.5 \mathrm{~min}$ & 5:20:00 & 6 & 0:04:30 \\
\hline & $\mathrm{L} 2 \mathrm{U} \rightarrow \mathrm{L} 1 \mathrm{D}$ & 14 & 5:19:00 & $1.5 \mathrm{~min}$ & 5:45:00 & 0 & $0: 24: 30$ \\
\hline & $\mathrm{L} 1 \mathrm{D} \rightarrow \mathrm{L} 2 \mathrm{D}$ & 9 & 5:44:00 & $1.5 \mathrm{~min}$ & 5:43:00 & 2 & 0:07:30 \\
\hline & $\mathrm{L} 2 \mathrm{D} \rightarrow \mathrm{L} 1 \mathrm{D}$ & 20 & 5:42:00 & $1.5 \mathrm{~min}$ & 5:45:00 & 0 & 0:01:30 \\
\hline \multirow{8}{*}{ 氖 } & $\mathrm{L} 1 \mathrm{U} \rightarrow \mathrm{L} 4 \mathrm{U}$ & 2 & 5:31:00 & $5 \mathrm{~min}$ & 5:29:00 & 1 & 0:03:00 \\
\hline & $\mathrm{L} 4 \mathrm{U} \rightarrow \mathrm{L} 1 \mathrm{U}$ & 8 & $5: 28: 00$ & $5 \mathrm{~min}$ & $5: 32: 00$ & 1 & 0:09:00 \\
\hline & $\mathrm{L} 1 \mathrm{U} \rightarrow \mathrm{L} 4 \mathrm{D}$ & 9 & $5: 31: 00$ & $5 \mathrm{~min}$ & 5:38:00 & 0 & 0:02:00 \\
\hline & $\mathrm{L} 4 \mathrm{D} \rightarrow \mathrm{L} 1 \mathrm{U}$ & 7 & $5: 37: 00$ & $5 \mathrm{~min}$ & 5:32:00 & 1 & 0:00:00 \\
\hline & $\mathrm{L} 1 \mathrm{D} \rightarrow \mathrm{L} 4 \mathrm{U}$ & 14 & 5:41:00 & $5 \mathrm{~min}$ & 5:29:00 & 2 & 0:03:00 \\
\hline & $\mathrm{L} 4 \mathrm{U} \rightarrow \mathrm{L} 1 \mathrm{D}$ & 4 & $5: 28: 00$ & $5 \mathrm{~min}$ & $5: 42: 00$ & 0 & 0:09:00 \\
\hline & $\mathrm{L} 1 \mathrm{D} \rightarrow \mathrm{L} 4 \mathrm{D}$ & 13 & $5: 41: 00$ & $5 \mathrm{~min}$ & 5:38:00 & 1 & 0:02:00 \\
\hline & $\mathrm{L} 4 \mathrm{D} \rightarrow \mathrm{L} 1 \mathrm{D}$ & 1 & $5: 37: 00$ & $5 \mathrm{~min}$ & $5: 42: 00$ & 0 & 0:00:00 \\
\hline \multirow{8}{*}{ 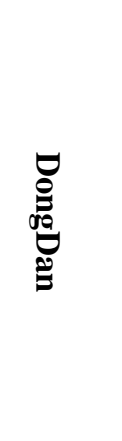 } & $\mathrm{L} 1 \mathrm{U} \rightarrow \mathrm{L} 5 \mathrm{U}$ & 10 & 5:40:00 & $3 \mathrm{~min}$ & $5: 35: 00$ & 1 & 0:02:00 \\
\hline & $\mathrm{L} 5 \mathrm{U} \rightarrow \mathrm{L} 1 \mathrm{U}$ & 8 & $5: 34: 00$ & $3 \mathrm{~min}$ & 5:41:00 & 0 & 0:04:00 \\
\hline & $\mathrm{L} 1 \mathrm{U} \rightarrow \mathrm{L} 5 \mathrm{D}$ & 6 & $5: 40: 00$ & $3 \mathrm{~min}$ & 5:41:00 & 1 & 0:08:00 \\
\hline & $\mathrm{L} 5 \mathrm{D} \rightarrow \mathrm{L} 1 \mathrm{U}$ & 6 & 5:40:00 & $3 \mathrm{~min}$ & $5: 41: 00$ & 1 & 0:08:00 \\
\hline & $\mathrm{L} 1 \mathrm{D} \rightarrow \mathrm{L} 5 \mathrm{U}$ & 12 & $5: 32: 00$ & $3 \min$ & $5: 35: 00$ & 0 & 0:00:00 \\
\hline & $\mathrm{L} 5 \mathrm{U} \rightarrow \mathrm{L} 1 \mathrm{D}$ & 10 & $5: 34: 00$ & $3 \min$ & 5:33:00 & 1 & 0:06:00 \\
\hline & $\mathrm{L} 1 \mathrm{D} \rightarrow \mathrm{L} 5 \mathrm{D}$ & 7 & $5: 32: 00$ & $3 \min$ & 5:41:00 & 0 & 0:06:00 \\
\hline & $\mathrm{L} 5 \mathrm{D} \rightarrow \mathrm{L} 1 \mathrm{D}$ & 16 & 5:40:00 & $3 \min$ & 5:33:00 & 1 & 0:00:00 \\
\hline
\end{tabular}




\begin{tabular}{|c|c|c|c|c|c|c|c|}
\hline \multirow{8}{*}{ 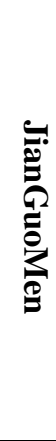 } & $\mathrm{L} 1 \mathrm{U} \rightarrow \mathrm{L} 2 \mathrm{U}$ & 11 & 5:43:00 & $1.5 \mathrm{~min}$ & 5:39:00 & 2 & 0:04:30 \\
\hline & $\mathrm{L} 2 \mathrm{U} \rightarrow \mathrm{L} 1 \mathrm{U}$ & 20 & 5:38:00 & $1.5 \mathrm{~min}$ & 5:44:00 & 0 & 0:04:30 \\
\hline & $\mathrm{L} 1 \mathrm{U} \rightarrow \mathrm{L} 2 \mathrm{D}$ & 5 & 5:43:00 & $1.5 \mathrm{~min}$ & $5: 24: 00$ & 5 & 0:04:30 \\
\hline & $\mathrm{L} 2 \mathrm{D} \rightarrow \mathrm{L} 1 \mathrm{U}$ & 16 & 5:23:00 & $1.5 \mathrm{~min}$ & 5:44:00 & 0 & 0:19:30 \\
\hline & $\mathrm{L} 1 \mathrm{D} \rightarrow \mathrm{L} 2 \mathrm{U}$ & 20 & 5:29:00 & $1.5 \mathrm{~min}$ & 5:39:00 & 0 & 0:08:30 \\
\hline & $\mathrm{L} 2 \mathrm{U} \rightarrow \mathrm{L} 1 \mathrm{D}$ & 20 & 5:38:00 & $1.5 \mathrm{~min}$ & 5:30:00 & 1 & 0:00:30 \\
\hline & $\mathrm{L} 1 \mathrm{D} \rightarrow \mathrm{L} 2 \mathrm{D}$ & 20 & 5:29:00 & $1.5 \mathrm{~min}$ & 5:24:00 & 1 & 0:03:30 \\
\hline & $\mathrm{L} 2 \mathrm{D} \rightarrow \mathrm{L} 1 \mathrm{D}$ & 13 & 5:23:00 & $1.5 \mathrm{~min}$ & 5:30:00 & 0 & $0: 05: 30$ \\
\hline \multirow{8}{*}{$\begin{array}{l}\Omega \\
\overline{0} \\
\frac{1}{0} \\
0\end{array}$} & $\mathrm{~L} 1 \mathrm{U} \rightarrow \mathrm{L} 10 \mathrm{U}$ & 15 & 5:49:00 & $4.5 \mathrm{~min}$ & 6:13:00 & 0 & $0: 19: 30$ \\
\hline & $\mathrm{L} 10 \mathrm{U} \rightarrow \mathrm{L} 1 \mathrm{U}$ & 11 & 6:12:00 & $4.5 \mathrm{~min}$ & 5:50:00 & 3 & 0:03:30 \\
\hline & $\mathrm{L} 1 \mathrm{U} \rightarrow \mathrm{L} 10 \mathrm{D}$ & 20 & 5:49:00 & $4.5 \mathrm{~min}$ & 5:55:00 & 0 & 0:01:30 \\
\hline & $\mathrm{L} 10 \mathrm{D} \rightarrow \mathrm{L} 1 \mathrm{U}$ & 10 & 5:54:00 & $4.5 \mathrm{~min}$ & 5:50:00 & 1 & 0:01:30 \\
\hline & $\mathrm{L} 1 \mathrm{D} \rightarrow \mathrm{L} 10 \mathrm{U}$ & 20 & 5:23:00 & $4.5 \mathrm{~min}$ & 6:13:00 & 0 & 0:45:30 \\
\hline & $\mathrm{L} 10 \mathrm{U} \rightarrow \mathrm{L} 1 \mathrm{D}$ & 19 & 6:12:00 & $4.5 \mathrm{~min}$ & $5: 24: 00$ & 6 & 0:07:30 \\
\hline & $\mathrm{L} 1 \mathrm{D} \rightarrow \mathrm{L} 10 \mathrm{D}$ & 15 & 5:23:00 & $4.5 \mathrm{~min}$ & 5:55:00 & 0 & $0: 27: 30$ \\
\hline & $\mathrm{L} 10 \mathrm{D} \rightarrow \mathrm{L} 1 \mathrm{D}$ & 14 & 5:54:00 & $4.5 \mathrm{~min}$ & 5:24:00 & 4 & 0:05:30 \\
\hline \multicolumn{5}{|c|}{ Transfer stations of line 1} & $\sum v_{s l l} \cdot t_{s l l^{\prime}}^{T W T}$ & 79 & $6774 \min$ \\
\hline \multicolumn{5}{|c|}{ All transfer stations in the network } & $\sum v_{s l l} \cdot t_{s l l}^{T W T}$ & 424 & $16380 \mathrm{~min}$ \\
\hline
\end{tabular}

